\title{
The Potassium Channel Subunit KV3.1b Is Localized to Somatic and Axonal Membranes of Specific Populations of CNS Neurons
}

\author{
M. Weiser, ${ }^{1}$ E. Bueno, ${ }^{1}$ C. Sekirnjak, ${ }^{2}$ M. E. Martone,${ }^{2}$ H. Baker, ${ }^{3}$ D. Hillman, ${ }^{1}$ S. Chen, ${ }^{1}$ W. Thornhill, ${ }^{4}$ \\ M. Ellisman, ${ }^{2}$ and B. Rudy ${ }^{1}$ \\ 'Department of Physiology and Neuroscience, New York University Medical Center, New York, New York 10016, \\ 'Laboratory for Neurocytology and Department of Neurosciences, University of California at San Diego, La Jolla, \\ California, ${ }^{3}$ Laboratory of Molecular Neurobiology, W. M. Burke Medical Research Institute, White Plains, New York, \\ and ${ }^{4}$ Department of Physiology and Biophysics, Mount Sinai Medical Center, New York, New York
}

Potassium channels play major roles in the regulation of many aspects of neuronal excitability. These channels are particularly well suited for such multiplicity of roles since there is a large diversity of channel types. This diversity contributes to the ability of specific neurons (and possibly different regions of the same neuron) to respond uniquely to a given input. Neuronal integration depends on the local response of spatially segregated inputs to the cell and the communication of these integration centers with the axon. Therefore, the functional implications of a given set of $\mathrm{K}^{+}$ channels varies depending on their precise location on the neuronal surface. Site-specific antibodies were utilized to characterize the distribution of KV3.1b, a subunit of voltage-gated $\mathrm{K}^{+}$channels in CNS neurons. KV3.1b subunits are expressed in specific neuronal populations of the rat brain, such as cerebellar granule cells, projecting neurons of deep cerebellar nuclei, the substantia nigra pars-reticulata, the globus pallidus, and the ventral thalamus (reticular thalamic nucleus, ventral lateral geniculate and zona incerta). The KV3.1b protein is also present in various neuronal populations involved in the processing of auditory signals, including the inferior colliculus, the nuclei of the lateral lemniscus, the superior olive, and some parts of the cochlear nuclei; as well as in several other neuronal groups in the brainstem (e.g., in the oculomotor nucleus, the pontine nuclei, the reticulotegmental nucleus of the pons, trigeminal and vestibular nuclei, and the reticular formation) and subsets of neurons in the neocortex, the hippocampus and the caudate-putamen shown by double staining to correspond to neurons containing parvalbumin. KV3.1b subunits are localized predominantly in somatic and axonal membranes (particularly in axonal terminal fields) but are much less prominent in dendritic arborizations. This distribution is different than that of other subunits of voltage gated $\mathrm{K}^{+}$channels and is consistent with a role in the modulation of action potentials. KV3.1b pro-

\footnotetext{
Received Oct. 26, 1994; revised Feb. 3, 1995; accepted Feb. 7, 1995.

This research was supported by an American Heart Association Research Grant, and NIH Grant NS30989 to B.R.; NIH Grant NS29633, to W.T; NIH Grants NS14718, NS26739, and RR04050 to M.E.; and NIH Grants NS13742 and $\mathrm{AG} 09480$ to D.H.

Correspondence should be addressed to B. Rudy, Department of Physiology and Neuroscience, New York University Medical Center, 550 First Avenue, New York, NY 10016.

Copyright (C) 1995 Society for Neuroscience $0270-6474 / 95 / 154298-17 \$ 05.00 / 0$
}

teins have a cellular and subcellular distribution different than the related KV3.2 subunits which express in Xenopus oocytes currents similar to those expressed by KV3.1b.

[Key words: reticular thalamus, cerebellum, granule cells, Interneurons, parnalbumin, antibodies]

Recombinant DNA techniques have revealed the existence of a large number of primary subunits of voltage-gated $\mathrm{K}^{+}$channels in mammals. These subunits have been classified in two groups (or families), both members of the S4 superfamily of ion channel proteins. The first group is usually divided in four subgroups (or subfamilies) each consisting of the homologs of the products of four closely related genes in Drosophila (Shaker, Shab, Shaw, and Shal) (Jan and Jan, 1990; Perney and Kaczmarek, 1991; Rudy et al., 1991a; Pongs 1992; Salkoff et al., 1992). The second family consists of proteins related to the product of the Drosophila eag gene (Warmke and Ganetzky, 1994). The genes and gene products of the first family (thereafter called collectively $\mathrm{Sh}$ ) have been studied most extensively. Individual Sh subunits form functional tetrameric voltage gated $\mathrm{K}^{+}$channcls when expressed in Xenopus laevis oocytes or other heterologous expression systems. In addition, subunits of the same Sh subfamily (but not of different subfamilies) can combine with each other leading to the formation of heteromultimeric channels with distinct functional properties (Christie et al., 1990; Isacoff et al., 1990; McCormack et al., 1990; Ruppersberg et al., 1990; Covarrubias et al., 1991; Weiser et al., 1994). Moreover, the channels formed by at least some Sh subunits can interact with auxiliary $(\beta)$ subunits which can modify channel properties (Chabala et al., 1993; Rettig et al., 1994; Scott et al., 1994; Serodio et al., 1994). Taking all these factors in consideration, these subunits can potentially result in the formation of several hundred functionally distinct voltage-gated $\mathrm{K}^{+}$channels. This large diversity could provide a mechanism to achieve subtle differences in neuronal integration.

However, the molecular composition of native voltage-gated $\mathrm{K}^{+}$channels is for the most part unknown. Although all known Sh and eag proteins are present in neurons, the channels containing these proteins have not been identified. Therefore, it is not known how much of the potential diversity predicted by molecular analysis is actually utilized by neurons or other cells.

In order to pursue this problem it is necessary to identify and charactcrizc the native channels containing a given subunit(s), a task which in turn requires identifying cells expressing the sub- 

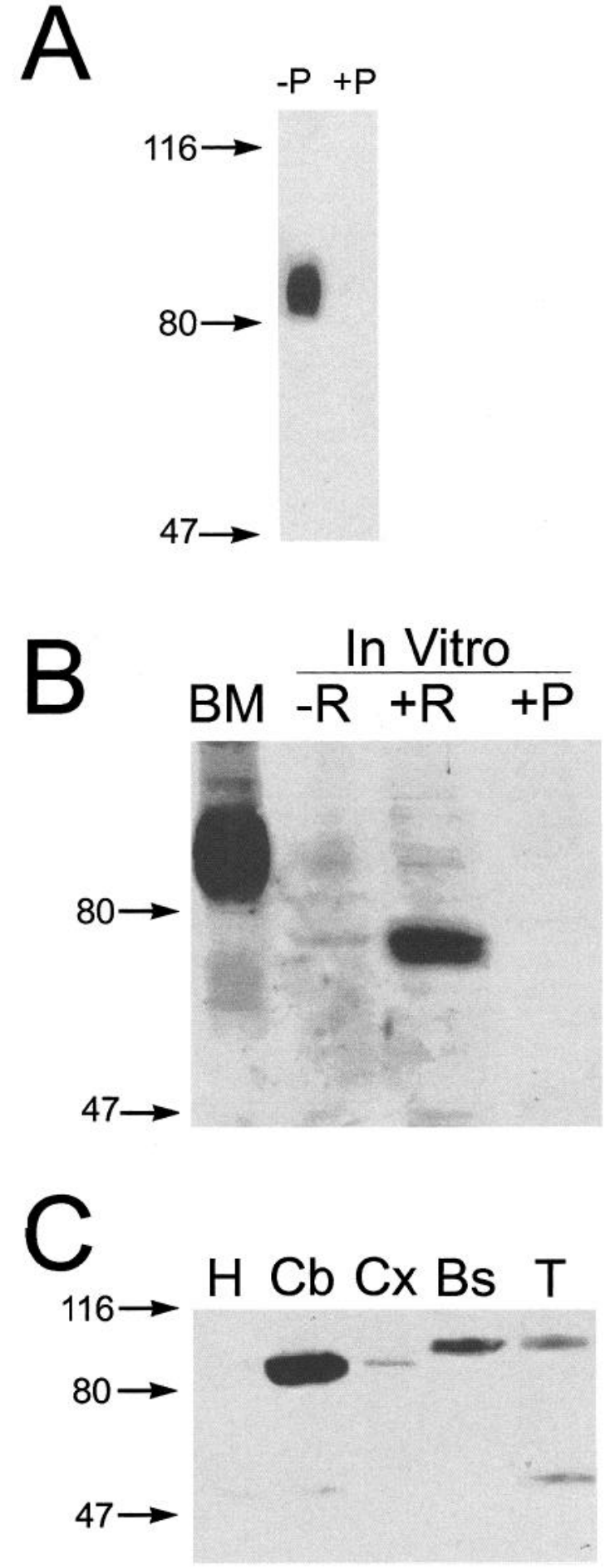

Figure 1. Immunoblot analysis of KV3.1b-specific antisera. A, Immunoblots of SDS gel fractionated rat brain membranes treated with KV3.1b antibodies $(-P)$ or with KV3.1b antibodies incubated with an excess of KV3.1b peptide $(+P)$. $B$, Immunoblots of SDS gel fractionated in vitro translated $\mathrm{KV} 3.1 \mathrm{~b}$ protein treated with $\mathrm{KV} 3.1 \mathrm{~b}$ antibodies $(+R)$ or with KV3.1b antibodies incubated with an excess of KV3.1b peptide $(+P)$ are compared to an immunoblot of SDS gel fractionated rat brain membranes $(B M)$ treated with $\mathrm{KV} 3.1 \mathrm{~b}$ antibodies. $-R$ shows an immunoblot of an in vitro translation reaction carried out without KV3.1b cRNA. $C$, Immunoblots of SDS gel fractionated membranes derived from various brain regions treated with $\mathrm{KV} 3.1 \mathrm{~b}$ antibodies. $H$, Hippocampus; $C b$, cerebellum; $C x$, cortex; $B s$, brainstem; $T$, thalamus. unit(s) of interest. It would then be possible to explore with electrophysiological methods whether those cells have channels with functional properties similar to those seen in heterologous expression systems.

The identification of native channels containing Shaw-related subunits is particularly challenging since in oocytes (Yokoyama et al., 1989; McCormack et al., 1990; Luneau et al., 1991; Rudy et al., 1991b; Vega-Saenz de Miera et al., 1992, 1994; Weiser et al., 1994) and in Chinese hamster ovary (CHO) cells (Moreno et al., 1995), they express channels that start activating only when the membrane is depolarized beyond $-20 \mathrm{mV}$ and are very sensitive to TEA and 4-AP. Under certain circumstances neurons may use such channels to regulate action potential duration instead of using $\mathrm{K}^{+}$channels activating at more negative voltages since the latter [in addition to affecting action potential duration] could also affect other features of excitability. Such speculations are interesting, however, there is no evidence that native channels containing Shaw subunits have properties similar to those of Shaw channels in heterologous expression systems. Moreover, although channels with these properties are not among the most typically recorded from CNS neurons, some Shaw mRNAs are as abundant in total brain RNA preparations as other $\mathrm{K}^{+}$channel transcripts (Weiser et al., 1994).

In situ hybridization studies exploring the expression of the mRNA products of the four known genes of the Shaw subfamily in the CNS have shown that these components are present in specific neuronal populations (Perney et al., 1992; Rudy et al., 1992; Weiser et al., 1994). Before proceeding with electrophysiological analysis of these neurons, it is necessary to investigate the localization of the proteins themselves at the subcellular level. For this purpose we are raising antibodies against Shaw proteins. The subcellular localization of KV3.1b proteins, the most abundant product of the KV3.1 gene in neurons of the rat brain, is presented in this article. The nomenclature of Sh genes and products proposed by Chandy et al. (1991) was used throughout this article.

Segregation of ion channels to specific parts of cells, including muscle fibers, epithelial cells, peripheral receptors and neurons is of enormous physiological significance (Almers and Sterling, 1984; Llinas, 1988; Shepherd, 1990; Kandel et al., 1991; Hille, 1992). For example, neuronal integration depends on the local response of spatially segregated inputs to the cell and the communication of these integration centers with the axon. Therefore, the functional implications of a given set of ion channels will depend on their precise location on the neuronal surface. The present study, therefore, in addition to providing information useful for the electrophysiological identification of native channels containing $\mathrm{KV} 3.1 \mathrm{~b}$ proteins, contributes to the knowledge of the arrays of distributions that channels may have in CNS neurons.

\section{Materials and Methods}

Antibody production. The peptide CKESPVIAKYMPTEAVRVT was synthesized at the Department of Pharmacology, New York University Medical Center. This peptide, corresponding to the carboxyl terminal sequence of the KV3.1b protein (residues 567-585) (Luneau et al., 1991), was coupled via the cysteine to keyhole limpet hemocyanin (KLH). The KLH-linked KV3.1b peptide was injected into rabbits using standard procedures for antiserum production by Berkeley Antibody Company (Richmond, CA). For affinity purification, the KV3.1b peptide was coupled to Sulfolink Sepharose resin (Pierce, Rockford, IL) via the cysteine residue and the antibodies purified following supplier's protocols. The preparation and characterization of KV3.2-specific antisera are described elsewhere (Moreno et al., 1995). 

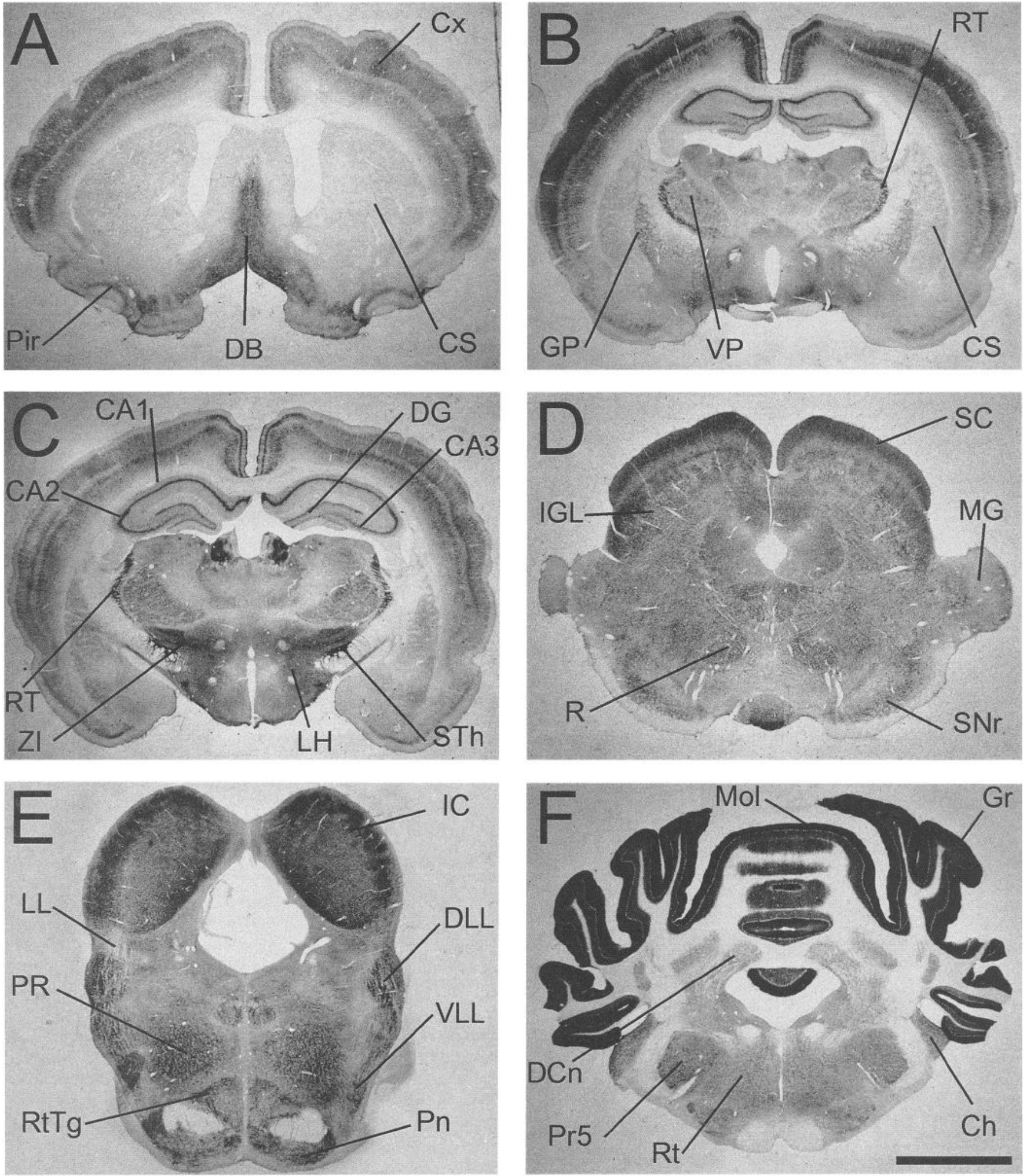

Figure 2. Immunolocalization of the KV3.1b protein in the rat brain. $A$, Coronal section at the level of the diagonal band of Broca. $B$, Coronal section at the level of the anterior portion of the hippocampus. $C$, Coronal section at the level of the subthalamic nucleus. $D$, Coronal section at the level of the superior colliculus (without the overlying cortex). E, Coronal section at the level of the inferior colliculus (without the overlying cortex). $F$, Coronal section at the level of the cerebellum. Note the specific regional expression of the KV3.1b protein (dark areas) and the lack of significant staining in the corpus striatum $(A$ and $B)$ and most of the dorsal thalamus $(B$ and $C)$ including the medial geniculate $(D)$. Abbreviations: $C A 1, \mathrm{CA} 1$ region of hippocampus; $C A 2$, CA2 region of hippocampus; $C A 3, \mathrm{CA} 3$ region of hippocampus; $C h$, cochlear nuclei; $C S$, corpus striatum; $C x$, cortex; $D B$, nucleus of the diagonal band of Broca; $D C n$, deep cerebellar nuclei; $D G$, dentate gyrus; $D L L$, dorsal lateral lemniscus nucleus; $G P$, globus pallidus; $G r$, granule cell layer of the cerebellar cortex; $I C$, inferior colliculus; $I G L$, intermediary gray layer; $M G$, medial geniculate; $\mathrm{Mol}$, molecular cell layer of the cerebellar cortex; Pir, piriform cortex; $P n$, pontine nucleus; $P R$, pontine reticular nucleus; $P r 5$, principal trigeminal nucleus; $R$, red nucleus; RT, reticular thalamic nucleus; $R t$, reticular formation; $R t T g$, reticulotegmental nucleus of the pons; $S C$, superior colliculus; 
In vitro translation. Wheat-germ lysate was utilized to prepare in vitro translated protein from $0.4 \mu \mathrm{g}$ of in vitro transcribed KV3.1b RNA as described in Erikson and Blobel (1983). The reaction was carried out at $28^{\circ} \mathrm{C}$ for $1 \mathrm{hr}$ and proteins TCA precipitated with $10 \%$ TCA and resuspended in SDS electrophoresis buffer.

Preparation of membrane extracts. Adult (150-200 gm) SpragueDawley rats werc decapitated and their brains removed. The desired brain areas were quickly dissected and immediately frozen in liquid $\mathrm{N}_{2}$ and stored at $-70^{\circ} \mathrm{C}$ until use. Lysed membranes ( $\mathrm{P} 3$ fractions) were prepared as described in Hartshorne and Catterall (1984) and solubilized in a $2 \%$ Triton X-100 solution containing $50 \mathrm{~mm}$ potassium phosphate buffer $\mathrm{pH} 7.4,50 \mathrm{~mm} \mathrm{KCl,} 2 \mathrm{~mm}$ EDTA, and $1 \mathrm{~mm}$ pepstatin A, $1 \mathrm{~mm}$ 1,10 phenanthroline, $0.2 \mathrm{mM}$ PMSF, and $1 \mathrm{~mm}$ iodoacetamide to inhibit proteases. Solubilized membranes were stored in $50 \%$ glycerol at $-20^{\circ} \mathrm{C}$ at $10-20 \mathrm{mg} / \mathrm{ml}$.

Immunoblot analysis. Solubilized membranes $(\sim 100 \mu \mathrm{g}$ of protein) were diluted with an equal volume of SDS sample buffer (10\% glycerol, $5 \% \beta$-mercaptoethanol; $0.001 \%$ (weight) bromphenol blue and $3 \%$ SDS in $60 \mathrm{~mm}$ Tris $\mathrm{pH} 6.8$ ), heated for $3 \mathrm{~min}$ at $80^{\circ} \mathrm{C}$, and electrophoresed in a $10 \%$ SDS polyacrylamide gel (Harlow and Lane, 1988). The electrophoresed proteins were transferred onto a nitroccllulose filtcr (BioRad) and the Western blot incubated with KV3.1b antibodies at a 1:5000 dilution, followed by incubation with horseradish peroxidaselinked anti-rabbit secondary antibodies prepared in donkey. Bound antibodies were detected using chemiluminescence with an ECL detection kit (Amersham).

Immunohistochemistry. Adult male (150-200 gm) Sprague-Dawley rats were deeply anesthetized with sodium pentobarbital (Nembutal; 120 $\mathrm{mg} / \mathrm{kg}$, i.p.) and perfused transcardially with saline containing $0.5 \%$ $\mathrm{NaNO}_{2}$ and $10 \mathrm{U} / \mathrm{ml}$ heparin sulfate followed by cold $4 \%$ formaldehyde generated from paraformaldehyde in $0.1 \mathrm{M}$ sodium phosphate buffer, $\mathrm{pH}$ 7.4. The brains were postfixed in the same fixative for $1 \mathrm{hr}$ and cryoprotected in $30 \%$ sucrose at $4^{\circ} \mathrm{C}$ overnight. Free-floating sections $(30$ $\mu \mathrm{m})$, obtained on a freezing microtome, were washed for $30 \mathrm{~min}$ in 0.1 $M$ sodium phosphate-buffered saline (PBS) and prcincubated with $1 \%$ bovine serum albumin (BSA, Sigma Fraction V) and $0.2 \%$ Triton X-100 in $0.1 \mathrm{M}$ PBS. The sections were then washed in PBS containing $0.5 \%$ BSA (PBS-BSA) and incubated overnight with KV3.1b (1:5000, unless otherwise indicated) or KV3.2 (1/100) antisera. After washing in PBSBSA the sections were incubated for $1 \mathrm{hr}$ with biotinylated anti-rabbit $\operatorname{IgG}(1: 200$, Vector Laboratories, Burlingame, CA). The tissue was washed and incubated for $1 \mathrm{hr}$ with the avidin-biotin horseradish peroxidase complex according to Vectastain Elite ABC kit instructions (Vector Laboratories). The antigens were visualized by reaction with the chromogen 3,3'-diaminobenzidine-tetrahydrochloride (DAB, Aldrich) and hydrogen peroxide for $5 \mathrm{~min}$. Sections were mounted on gelatin-coated slides, dehydrated through graded ethanols, counterstained with cresyl violet when necessary, and coverslipped with Permount (Fisher Scientific, St. Louis, MO). The atlas by Paxinos and Watson (1986) and the book by Paxinos (1985) were used as guides to identify CNS neuronal populations and axonal projections.

Some HRP-reacted sections were embedded in plastic for analysis with light and electron microscopy. These sections were postfixed in $1 \%$ osmium tetroxide for 20 min, dehydrated in ethyl alcohol, and flat embedded in Durcupan (FIuka) by sandwiching between two sheets of polyethylene. The embedded slices were viewed directly through the plastic with the light microscope and ultrathin sections were made and mounted on grids for observation in a JEOL electron microscope.

In situ hybridization histochemistry. Adult male Sprague-Dawley rats were perfused and brains were sectioned as above. Sections $(40 \mu \mathrm{m})$ were processed for in situ hybridization histochemistry with a KV3.1or a KV3.2-specific probe as previously described (Weiser et al., 1994).

Immunofluorescence. For immunofluorescence Sprague Dawley rats were perfused with a fixative containing $4 \%$ formaldehyde and $0.1 \%$ glutaraldehyde. Coronal sections $(80 \mu \mathrm{m})$ were cut on a vibratome (Lanzer series 1000 ) and placed in $0.1 \mathrm{M}$ PBS for $20 \mathrm{hr}$ at $4^{\circ} \mathrm{C}$ to remove the fixative. After four washes in PBS glycine ( $0.1 \%$ glycine), the sections were incubated for $30 \mathrm{~min}$ in a blocking buffer (1\% normal donkey serum, $1 \% \mathrm{BSA}, 1 \%$ fish gelatin, $0.5 \%$ 'riton-X100 in PBS). Following a $20 \mathrm{~min}$ rinse in working buffer $1 \%$ normal donkey serum,
$0.1 \%$ BSA, $0.1 \%$ fish gelatin, $0.1 \%$ Triton $\mathrm{X}-100$ in PBS) primary antibodies were added. The sections were incubated overnight in rotating vials at $4^{\circ} \mathrm{C}$. Following six washes (10 min each) in working buffer, fluorescent secondary antibodies were applied for $1 \mathrm{hr}$. After five rinses in PBS the sections were mounted on glass slides and treated with antifade medium. The slides were coverslipped, sealed with nail polish, and stored at $4^{\circ} \mathrm{C}$.

The following primary antibody concentrations were used: affinity purified KV3.1b antibodies at a 1:50 dilution and antibodies against parvalbumin (raised in mouse, Sigma Chemicals) at 1:100. As secondary antibodies we used FITC-(fluorescein) labeled anti-rabbit IgG (prepared in donkey, Jackson Immuno Research Laboratories) for KV3.1b staining and LSRC (lissamine rhodamine)-labeled anti-mouse IgG (prepared in donkey, Jackson Immuno Research Laboratories) for parvalbumin staining. Both were applied at a 1:75 dilution.

To visualize the labeling we used a confocal microscope (Zeiss Axiovert $35 \mathrm{M}$ ) equipped with a fluorescence detection system (Bio-Rad MRC 600) and an argon-krypton mixed gas laser. Pictures were collected digitally and transferred to a graphics program (Adobe PHOTOSH$\mathrm{OP}$ ). The picture files were pseudocolored and printed on a color printer (Tcktronix).

\section{Results}

\section{Characterization of $K V 3.1 b$-specific antibodies}

There are two known transcripts of the KV3.1 gene called KV3.1a and KV3.1b. These transcripts are generated via alternative splicing and predict proteins that differ only in their carboxyl ends; in the KV3.1b protein, the last 10 amino acids of KV3.1a are replaced by 84 residues (Luneau et al., 1991). Northern blot analysis and in situ hybridization studies show that $\mathrm{KV} 3.1 \mathrm{~b}$ is by far more abundant than KV3.1a in the adult rat brain (Luneau et al., 1991; Perney et al., 1992; Rudy et al., 1992; Vega-Saenz de Miera et al., 1994). Antibodies specific for the KV3.1b protein were raised in rabbits immunized with a peptide corresponding to the C-terminal 19 residues of $\mathrm{KV} 3.1 \mathrm{~b}$.

On immunoblots of denatured protein extracts of rat brain membranes, the antibodies recognize a diffuse band of 80-90 $\mathrm{kDa}$ (Fig. 1A, lane $-\mathrm{P}$ ). This band is not seen when the immunoblots are reacted with antibodies preincubated with an excess of the KV3.1b peptide (Fig. 1A, lane + P). The antibodies also react with in vitro synthesized $\mathrm{KV} 3.1 \mathrm{~b}$ protein. In this case the band seen on immunoblots is $\sim 70 \mathrm{kDa}$ (Fig. $1 B$, lane $+\mathrm{R}$ ), similar to the expected molecular weight of $65,860 \mathrm{Da}$ of the KV3.1b polypeptide (Luneau et al., 1991). The immunostaining of this band is also prevented by preincubating the antibodies with KV3.1b peptide (Fig. $1 B$, lane $+\mathrm{P}$ ) and is not seen on immunoblots of in vitro translation reactions lacking $\mathrm{KV} 3.1 \mathrm{~b}$ cRNA (Fig. $1 B$, lane $-\mathrm{R}$ ). The size of the protein recognized in brain membrane extracts (Fig. $1 B$, lane BM) is significantly larger than the core polypeptide, suggesting that in vivo, the KV3.1b polypeptide has undergone processing such as glycosylation.

The protein recognized by KV3.1b antibodies is much more abundant in membranes derived from the ccrcbcllum than in membranes derived from other brain areas (Fig. $1 C$ ), as was the case for KV3.1 mRNAs (Perney et al., 1992; Rudy et al., 1992; Weiser et al., 1994). In fact, the relative levels of intensity of the $80-90 \mathrm{kDa}$ band in membranes from several brain regions (cerebellum $\gg$ brainstem $>$ thalamus $>$ cortex $\sim$ hippocampus) correspond to the relative levels of KV3.1 mRNAs in these various areas of the brain (Perney et al., 1992; Rudy et al., 1992; Weiser et al., 1994). Interestingly, the size of the band recog- 

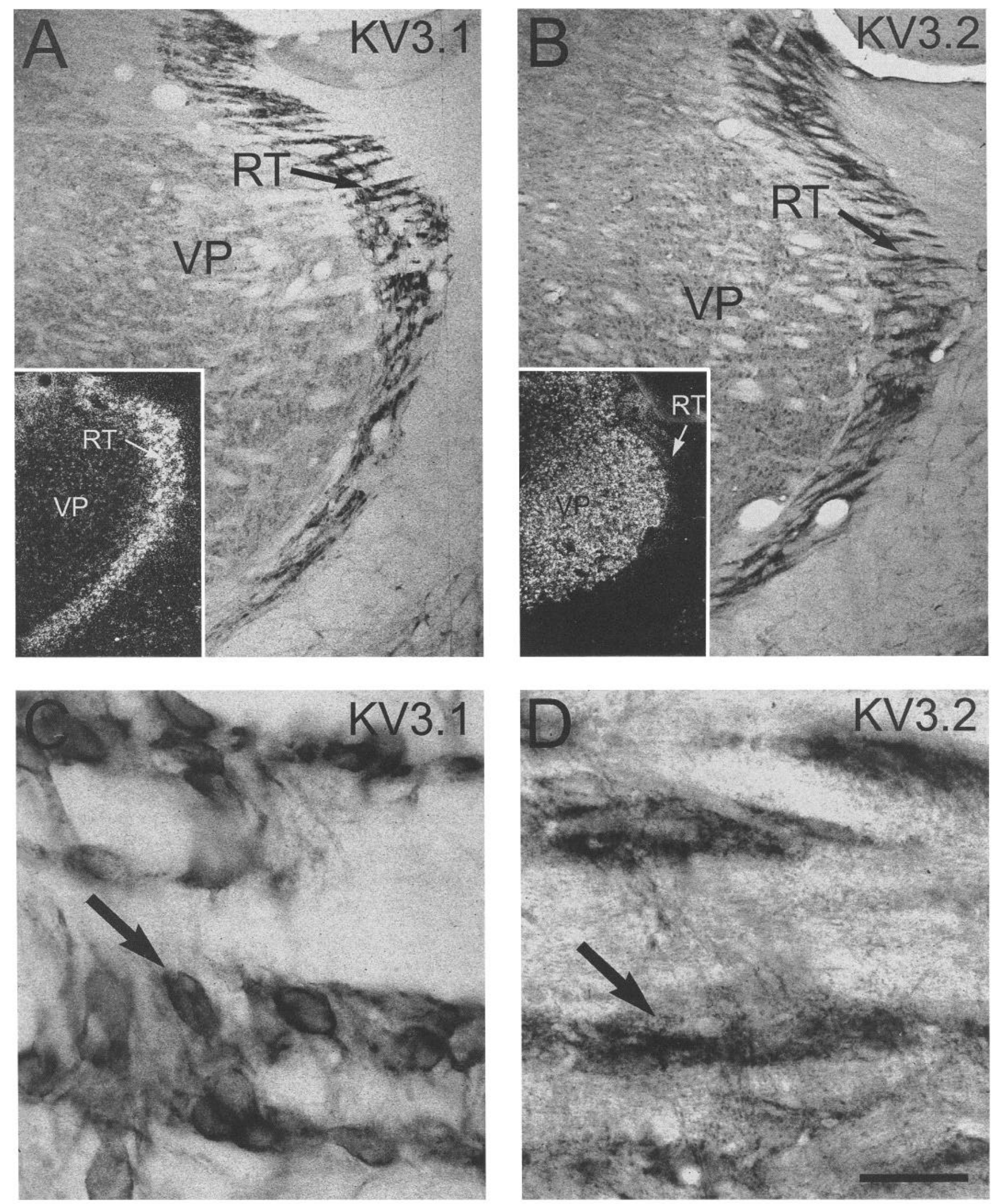

Figure 3. Localization of KV3.1b and KV3.2 proteins in the reticular thalamic nucleus $(R T)$ and the ventral posterior complex $(V P)$ of the dorsal thalamus. $A$ and $B$, Low power bright-field photomicrograph of the RT and VP following immunostaining with antibodies directed against KV3.1b and KV3.2 specific peptides. Note strong immunostaining of the RT with both KV3.1b $(A)$ and KV3.2 $(B)$ antibodies although only KV3.1 mRNAs are strongly expressed in this nucleus (see insets in $A$ and $B$ and Weiser et al., 1994). KV3.2 mRNAs are concentrated instead in thalamic relay neurons in most nuclei of the dorsal thalamus, such as in the nuclei of the ventral posterior complex shown here. $C$ and $D$, High power bright- 
nized by the antibody is not the same in membrane extracts from different brain areas. This is unlikely to be the result of nonspecific proteolytic activity since we have observed the same differences with three different membrane preparations. Similar differences were also described for the KV1.2 protein (Sheng et al., 1994) and may reflect differential posttranslational processing. The functional significance of this is unclear, but could be clarified with further studies to understand the molecular nature of the differences.

The KV3.1b antibodies were also useful for immunocytochemical studies of brain sections. The pattern of antibody staining of the rat brain was consistent with the pattern of mRNA localization by in situ hybridization as discussed throughout this article, providing further evidence for their specificity. Furthermore, the immunostaining in brain sections was blocked by preincubating the antibodies with the KV3.1b peptide (data not shown).

\section{Similar distributions of KV3.1 mRNA transcripts and KV3.1b proteins in rat brain}

Studies of the distribution of KV3.1 mRNAs in the rat CNS utilizing in situ hybridization histochemistry showed that KV3.1 transcripts are present in a specific subset of neuronal populations. Most prominent was the labeling of the cerebellar cortex (Perney et al., 1992; Rudy et al., 1992; Weiser et al., 1994).

In the present study, we found that, for the most part, there was a correspondence between the relative levels of KV3.1b protein and mRNA in different brain regions (compare Fig. 2 with Weiser et al., 1994). The cerebellar cortex was also the area displaying strongest signals in immunohistochemistry (Fig. 2F). Other regions with strong to moderate immunostaining also correspond to regions expressing high to moderate mRNA levels, for example, the reticular thalamic nucleus (RT, Fig. $2 B, C$ ), the inferior colliculus (IC, Fig. $2 E$ ), the subthalamic nucleus and the zona incerta (STh and ZI, Fig. 2C), the substantia nigra pars reticulata ( $\mathrm{SNr}$, Fig. $2 D$ ), the pontine nuclei $(\mathrm{Pn})$, reticulotegmental nucleus of the pons (RtTg), pontine reticular nucleus ( $P R$ ), and the nuclei of the lateral lemniscus (DLL, VLL) (Fig. 2E), as well as several neuronal groups in the hindbrain (Fig. $2 F$ ) including the ventral cochlear nucleus (Ch), various parts of the trigeminal (i.e., Pr5) and reticular nuclei (Rt), and others not shown here. At the same time, regions which appear to express relatively less protein, such as the caudate-putamen (CS, Fig. $2 A, B$ ), the medial geniculate (MG) and several other nuclei of the dorsal thalamus (Fig. $2 B-$ $D$ ) also correspond to regions where mRNA levels appeared to be low or absent.

The correspondence between mRNA and protein distribution is further illustrated in the RT. Both KV3.1 mRNA (see inset in Fig. 3A) and KV3.1b protein (Fig. $3 A$ ) are concentrated on the RT with lower levels of expression in the dorsal thalamus. Since the mRNA is usually concentrated in the cytoplasm of the cell bodies of expressing neurons, the overall correspondence between mRNA and protein localization in the case of KV3.1b suggests that in most neuronal populations expressing KV3.1 mRNA there is protein in the somatic compartment.

There are a few discrepancies between KV3.1 mRNA and protein localization. There are three brain areas which express little or no KV3.1 mRNA but show strong signals in immunohistochemistry. One of these is the superior colliculus (SC). In this brain area we found KV3.1 mRNA only in scattered neurons in the intermediary gray layer (IGL) (Weiser et al., 1994). Protein is also present in these cells (Fig. 2D); however, superficial layers of the superior colliculi were also strongly stained by the antiserum (Fig. 2D).

There is also a lack of correspondence between mRNA expression and immunostaining in the hypothalamus. Here the mRNA was present in a few scattered neurons that were not identified further (Weiser et al., 1994). In the present study, we found that in addition to somatic staining of hypothalamic neurons in preoptic nuclei and others, there is a diffuse immunostaining of the neuropile throughout the hypothalamus, particularly strong in the lateral portion (LH, Fig. 2C). The third major discrepancy between protein and mRNA localization was observed in the cerebellar cortex. Protein levels appear to be very high in both the molecular ( $\mathrm{Mol}$ ) and granule $(\mathrm{Gr})$ cell layers (Fig. $2 F$ ), but the mRNA was localized mainly in granule cells. As discussed below, this discrepancy is due to the presence of KV3.1b protein in the axons of the granule cells, the parallel fiber system. Thus, the immunostaining in the superficial layers of the superior colliculus and the hypothalamus may also be due to the presence of protein in axons projecting from KV3.1b expressing neurons.

We have also found one neuronal population, the mitral cells of the olfactory bulb, where mRNA was present but little or no protein was detected (see below). Similarly, Weiser et al. (1994) reported that cerebellar Purkinje cells in the flocculus had low but above background expression of KV3.1 mRNA, but here we find no immunostaining of floccular Purkinje cell somata.

\section{$K V 3.16$ protein in somatodendritic membrane}

The localization of KV3.1b protein in the somatic membrane of several neuronal populations is further illustrated in Figures 39. Somatodendritic staining with the KV3.1b antibodies is clear in neurons of the RT (Fig. $3 A, C$ ). The specificity of this image is emphasized by comparing it to that produced by antibodies against the related KV3.2 $\mathrm{K}^{+}$channel subunits which, in the RT, only stain fibers (Moreno et al., 1994; see also Fig. 3B,D) thought to correspond to the collaterals of axons from thalamic relay neurons (Moreno et al., 1994).

Strong immunostaining with KV3.1b antibodies was also observed in the cell bodies and proximal dendrites of neurons in the globus pallidus (GP, Fig. $4 A, B$ ), subsets of neurons in the cerebral cortex, hippocampus and corpus striatum (Figs. 5, 6), as well as in the granule cells of the cerebellum (Fig. 7B,C).

Somatodendritic KV3.1b protein was also seen in several other neuronal populations expressing KV3.1b mRNA (Table 1). The somas of most neuronal types expressing the mRNA were clearly immunostained by the antibody. Often there is staining

$\leftarrow$

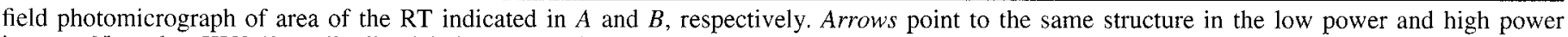

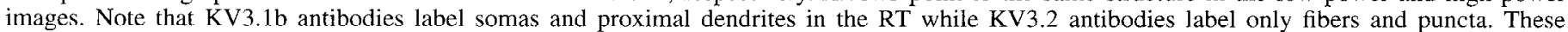

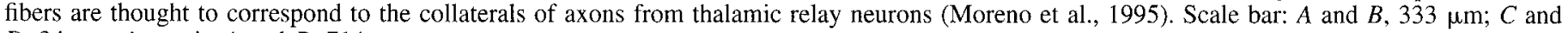
$D, 34 \mu \mathrm{m}$; insets in $A$ and $B, 714 \mu \mathrm{m}$. 

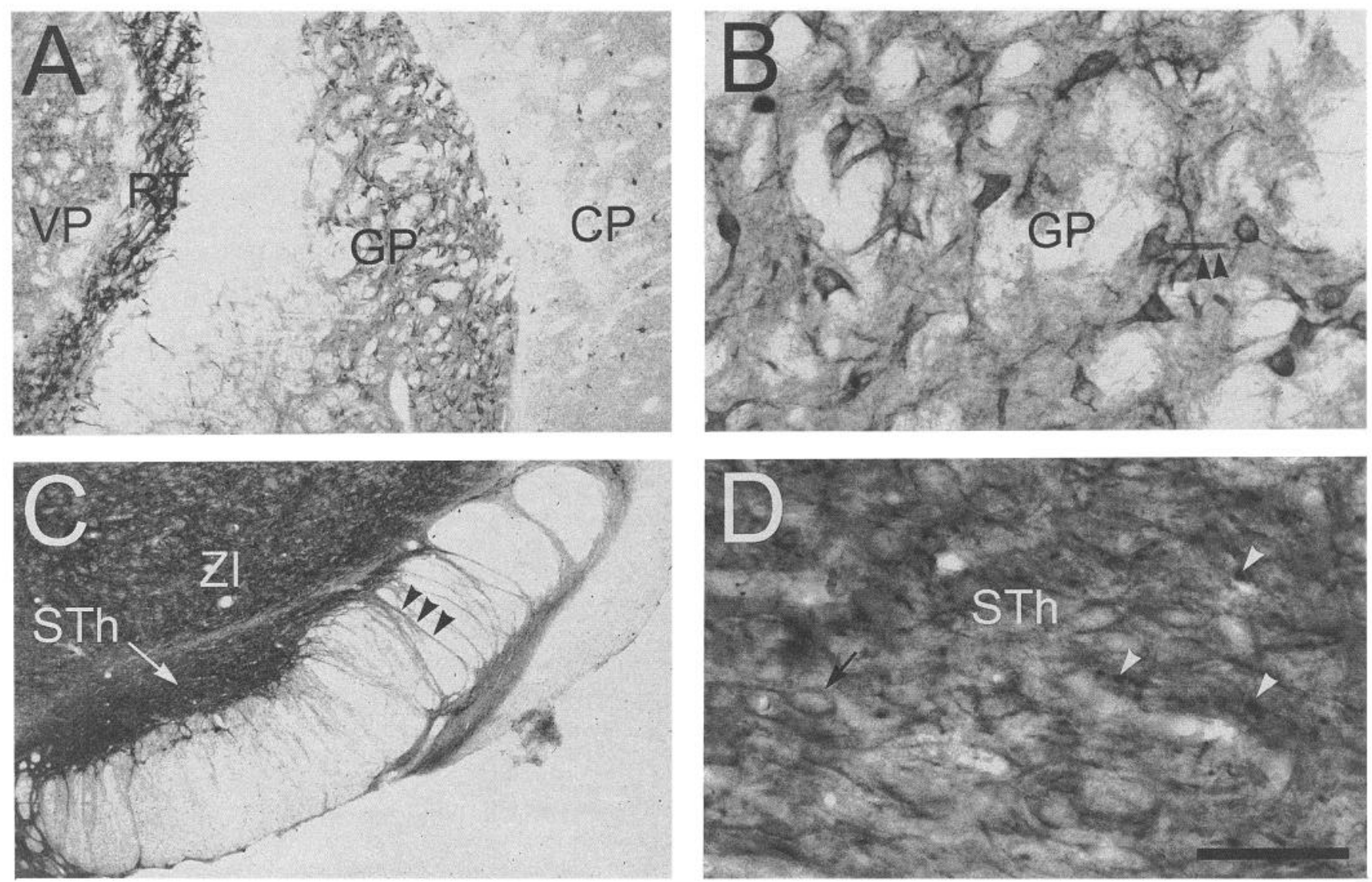

Figure 4. Localization of KV3.1b subunits in the globus pallidus $(G P)$ and the subthalamic nucleus $(S T h)$. Low power bright-field photomicrograph of the GP $(A)$ and STh $(C)$ following immunostaining with antibodies directed against KV3.1b-specific peptides. $B$ and $D$, High power bright-field photomicrograph of area seen in $A$ and $C$, respectively. Note in $B$, that in the GP, KV3.1b antibodies label somas and proximal dendrites (double arrowheads). In $C$ fibers corresponding to the axonal projections between the globus pallidus and the STh are clearly labeled (see triple arrowheads). $D$ shows the outline staining of neuronal somata in the STh (arrow), and strong labeled puncta (arrowheads). Other abbreviations: $C P$, caudateputamen; $V P$, ventral posterior thalamic complex; $R T$, reticular thalamic nucleus; $Z I$, zona incerta. Scale bar: $A, 700 \mu \mathrm{m} ; B$ and $D, 80 \mu \mathrm{m} ; C, 430$ $\mu \mathrm{m}$.

of the cytoplasm, particularly close to the membrane, as seen for other membrane proteins (Ellisman and Levinson, 1982; Ariyasu et al., 1987; Black et al., 1989). However, in some cases, such as the subthalamic nucleus (STh, Fig. 4D) the staining of cell bodies was faint and the surrounding neuropil was strongly stained.

In some instances the lack of contrast in the stãining of somas and surrounding fibers made it difficult to decide whether the somatic staining seen in those areas was due to the presence of protein in somatic membrane or whether it was the result of the presence of protein in terminals surrounding the cell body. For example, in the hippocampus low levels of mRNA were found in pyramidal cells of the CA1 and CA3 field of Ammon's horn and granule cells in the dentate gyrus in addition to the strong staining of a subset of interneurons (Weiser et al., 1994). As discussed below the soma and axon of the interneurons were strongly immunostained by the antibody, however, due to the staining of the axonal plexus of interneurons in the pyramidal and granule cell layers it was difficult to decide whether the cell bodies of pyramidal and granule cells were also stained. Other examples such as this one are listed in Table 1 as inconclusive.
Expression of KV3.1b subunits in subpopulations of neurons in the cerebral cortex, hippocampus, and corpus striatum

One of the interesting results of the in situ hybridization studies investigating the expression of mRNA transcripts for several Shaw $\mathrm{K}^{+}$channel genes including KV3.1 and the related gene KV3.2 (Weiser et al., 1994) was the finding that these genes were expressed in distinct subsets of neurons in the cortex, hippocampus, and caudate-putamen. Based on the distribution of labeled cells, Weiser et al. (1994) suggested that the mRNA was present in interneurons.

Strong immunostaining with the KV3.1b antibodies was also seen in a subset of neurons in the neocortex, hippocampus and corpus striatum (Fig. 5). The distribution of these cells is the same to that obtained by in situ hybridization (Weiser et al., 1994), but the immunocytochemistry has allowed further identification of these cells.

In the hippocampus, most of the stained cells have somas on the stratum pyramidalis close to the borders with the stratum oriens and the stratum radiatum as well as on the subgranular zone of the dentate gyrus (Fig. $5 C, D$ ), and are mostly basket cells (Fig. 5D). A few stained cells are present in the stratum oriens proper and in the hilus (Fig. $5 C$ ). Similarly stained cells 

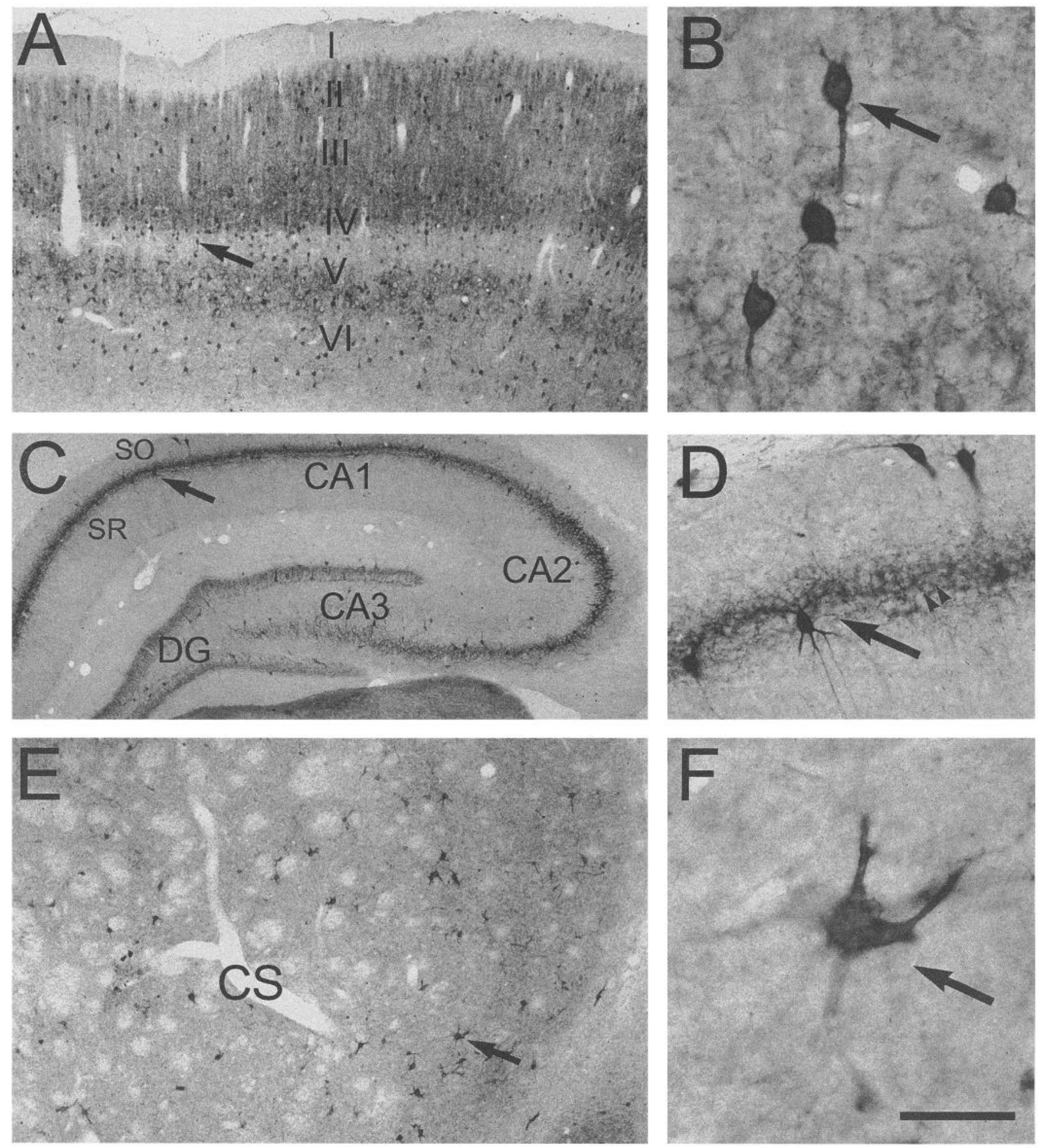

Figure 5. Expression of KV3.1b proteins in subsets of neurons in the neocortex, the hippocampus and the corpus striatum (CS). Low power bright-field photomicrograph of the neocortex $(A)$, the hippocampus $(C)$, and the CS $(E)$ following immunostaining with antibodies directed against KV3.1b-specific peptides. Note that labeled cells are distributed throughout layers II-VI in the neocortex and throughout the corpus striatum. In the hippocampus stained somas are located mainly along the borders of the stratus pyramidalis with the stratum oriens ( $S O$ ) and stratum radiatum $(S R)$ as well as on the edges of the stratum granulosum of dentate gyrus $(D G) ; B, D$, and $F$, High power bright-field photomicrograph of area seen in $A, C$, and $E$, respectively. Arrows point to the same cell in the low power and high power images. Note the strong labeling of somas and proximal dendrites of neurons in the three brain areas. In the hippocampus $(D)$ there is also labeling of the axonal plexus in stratus pyramidalis and weak staining of fine dendrites in the stratum radiatum. In these experiments, KV3.1b antibodies were used at a 1:1000 dilution to illustrate the weak staining of secondary dendrites in hippocampal interneurons, but not in the cortex and caudate-putamen. Abbreviations: $C A 1, C A 2, C A 3, \mathrm{CA} 1$, $\mathrm{CA} 2$, and CA3 region of hippocampus. Scale bar: $A, 570 \mu \mathrm{m} ; B, 50 \mu \mathrm{m} ; C, 727 \mu \mathrm{m} ; D, 100 \mu \mathrm{m} ; E, 400 \mu \mathrm{m} ; F, 28.5 \mu \mathrm{m}$. 

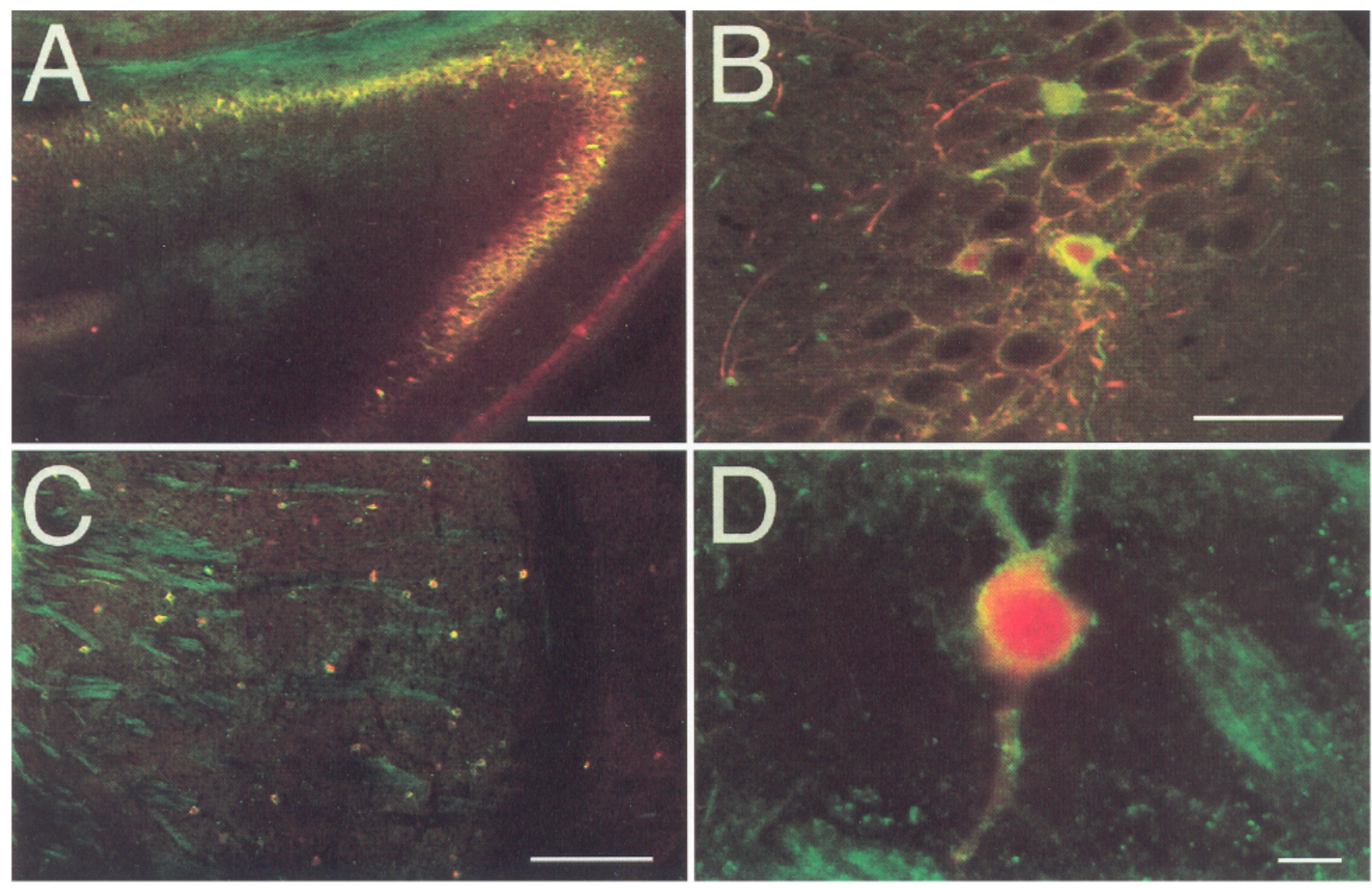

\section{KV3.1b antibody}

\section{Parvalbumin antibody}

Figure 6. Colocalization of KV3.1b subunits and parvalbumin. Confocal immunofluorescent images of sections of hippocampus ( $A, B)$ and striatum or caudate-putamen $(C, D)$ double labeled for the KV3.1b subunit (green) and parvalbumin $(P V)$ (red). A, Low magnification image of the CA2 and CA3 regions. The somas of interneurons are seen as yellow spots, indicating colocalization of KV3.1b protein and PV. Note the stratum pyramidale also appearing in yellow color. $B$, The soma and axon plexus of interneurons in the CA3 region exhibit colocalization of KV $3.1 \mathrm{~b}$ protein and PV producing yellow color. $C$, Caudate-putamen near the corpus callosum at low magnification. PV- and KV3.1b protein-containing neurons appear as yellow spots. $D$, The soma and proximal dendrites of a neostriatal neuron at high magnification. Scale bars: $A$ and $C, 300 \mu m ; B, 50$ $\mu \mathrm{m} ; D, 10 \mu \mathrm{m}$.

were also seen in the subiculum (data not shown). The numbers, distribution and morphology of these cells are very similar to those of a subset of GABA-containing interneurons in the hippocampus which display parvalbumin-like immunoreactivity (Celio and Heizmann, 1981; Kozaka et al., 1987; Sloviter 1989; reviewed in Celio, 1990).

To examine this further we utilized double labeling with the KV3.1b antibodies (raised in rabbit) and antibodies against parvalbumin (PV) (raised in mouse), and explored the staining of cells by immunofluorescence in a confocal microscope (Fig. $6 A, B)$. Anti-rabbit and anti-mouse secondary antibodies with two different fluorescent markers (see Materials and Methods) were used to distinguish between KV3.1b and PV immunostaining. Most cells immunostained for KV3.1b (green) are also stained for parvalbumin (red) and vice versa. Outside of the center of the cell, both labels tend to overlap producing a yellow color (Fig. 6B).
In the cortex, the neurons expressing KV3.1b protein are of the multipolar or bitufted type (Fig. $5 B$ ), are present throughout layers II-VI, and are also immunopositive for PV (not shown).

We also found that the KV3.1b antibodies stained a small number of dispersed cells in the caudate-putamen (Fig. $5 E, F$ ), as was reported for the mRNA (Weiser et al., 1994). These are usually multipolar cells, with somas of $20 \mu \mathrm{m}$ in diameter. Double staining with the parvalbumin antibody demonstrates (Fig. $6 C, D)$ that these cells also contain this $\mathrm{Ca}^{2+}$-binding protein.

\section{$K V 3.16$ protein in dendrites}

Dendritic staining was seen in most KV3.1b-labeled somata (see Figs. 3-8). However, in most cases strong staining was confined to proximal dendrites with little or no staining of most of the dendritic arborization (see, e.g., Figs. $3 C, 4 B, 5 B, F, 7 C$ ). With higher concentrations of the antibody (1:1000 instead of 1:5000) we could see very faint staining of secondary dendrites of some 


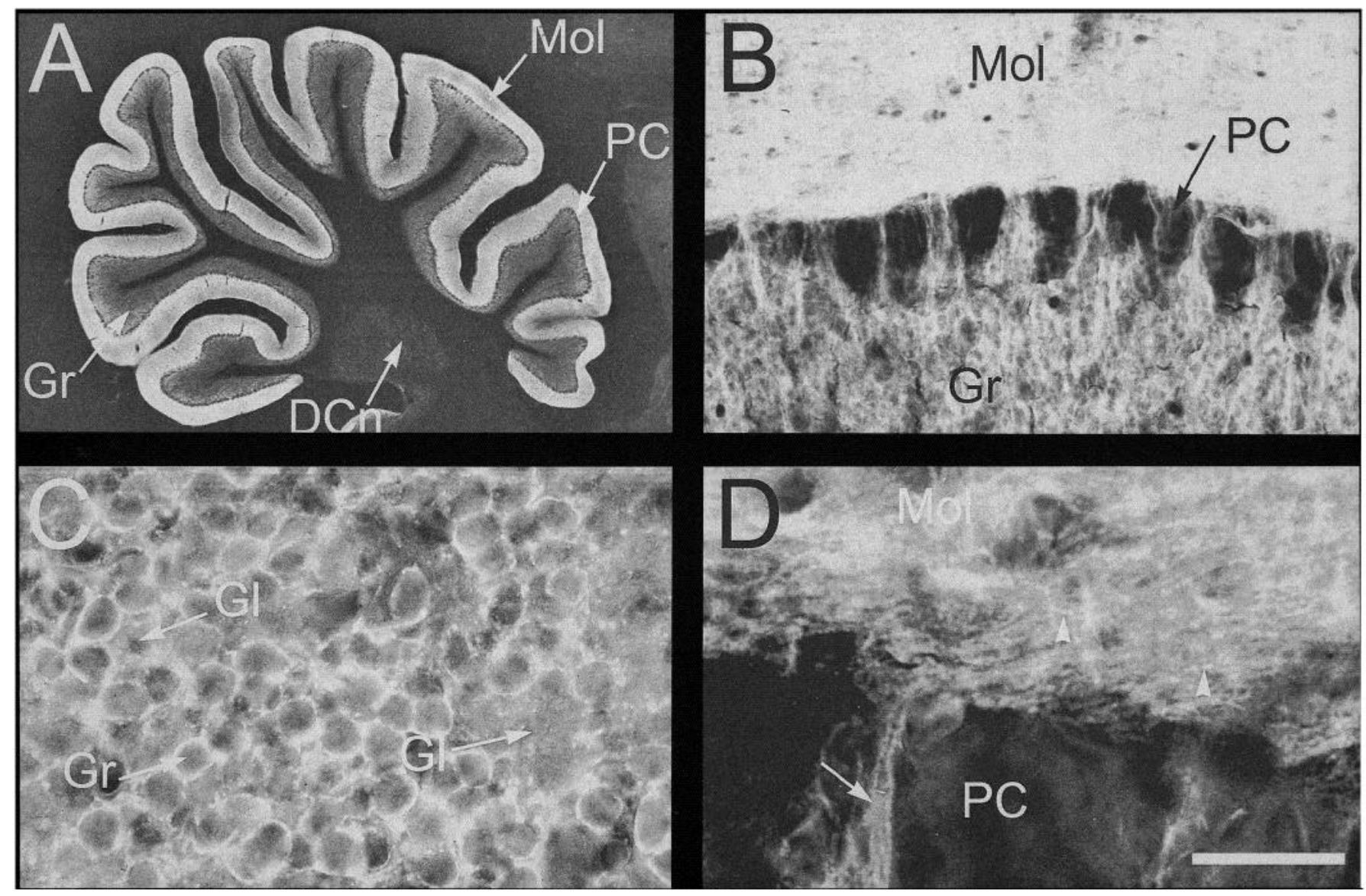

Figure 7. Immunolocalization of KV3.1b proteins in the cerebellar cortex. $A$, Low power bright-field photomicrograph of a coronal section of the cerebellum following immunostaining with antibodies directed against KV3.1b-specific peptides. $B$, Amplification of the cerebellar cortex of the image in $A$ illustrating the layer of granule cells $(G r)$, the Purkinje cells $(P C)$, and the molecular cell layer $(\mathrm{Mol})$. $C$, High power photomicrograph of the granule cell layer illustrating the labeling of granule cell somata. Note that the glomeruli are only faintly stained. $D$, High power photomicrograph of the boundary between the Purkinje cell layer and the molecular layer illustrating the immunostained ascending (arrow) and parallel fibers (arrowheads) of the axons of granule cells. Also note the punctate staining along the parallel fibers in the molecular cell layer. Scale bar: $A$, $1.7 \mathrm{~mm} ; B, 70 \mu \mathrm{m} ; C, 25 \mu \mathrm{m} ; D, 16 \mu \mathrm{m}$.

hippocampal interneurons (Fig. 5D). However, even at 1:1000 or even higher concentrations of antibody we were unable to see much staining of secondary dendrites in most neuronal populations expressing high levels of somatic KV3.1b protein, for example, in the neurons of the cortex and the caudate-putamen (Fig. $5 B, F$, respectively).

\section{The KV3:1b protein is also present in the membrane of projecting axons and terminals}

Many brain areas show immunostaining not associated with cell bodies. For example, in the subthalamic nucleus (Fig. $4 D$ ), besides the outline staining of cell bodies, numerous fine stained fibers were seen. In addition the antibody labeled puncta, suggestive of the presence of protein in axonal terminals or other axonal swellings (indicated by arrowheads in Fig. 4D). Faintly stained fibers are also present in the cerebral peduncle that appear to be entering (or leaving) the subthalamic nucleus (arrowheads, Fig. $4 C$ ) with a pattern resembling that of the axonal projections between the globus pallidus and the subthalamic nucleus (Carpenter et al., 1981a,b).

The KV3.1b protein is also present in the axons of the hippocampal interneurons described above. In addition to the somatic staining of these neurons there is a fine net-like pattern of labeling in the stratum pyramidalis of the CA1-CA3 fields of
Ammon's horn (Figs. 5D, 6A,B) and the stratum granulosum (not shown). These fibers are stained both with KV3.1b and PV antibodies and are yellow with the double staining method used (Fig. 6A,B). The pattern is very similar to that produced by the axonal plexus of hippocampal interneurons (Kozaka et al., 1987; Katsumaru et al., 1988; Sloviter, 1989).

More compelling evidence of axonal expression of $\mathrm{KV} 3.1 \mathrm{~b}$ protein was obtained in the cerebellar cortex. The highly organized cytoarchitecture characteristic of this structure facilitates the analysis enormously. The molecular cell layer of the cerebellar cortex was strongly labeled by the KV3.1b antibodies (Fig. 7A,B). The intensity of the label in the molecular layer is even stronger than that seen in the granule cell layer where the mRNA is concentrated (Weiser et al., 1994). This labeling could not result from protein present in the scattered basket and stellate cells, although these cells do express low levels of KV3.1 mRNA. Observation of the molecular cell layer at higher magnification (Fig. $7 B, D$ ) suggests that the labeling in this area is due to protein present in the parallel fiber system, the axons of the granule cells. The ascending fibers of the parallel fiber system are labeled; these are clearly seen as they cross the unlabeled Purkinje cells (Fig. 7B,D). The parallel collaterals are also stained producing the pattern of fine horizontal lines seen in Figure 7, $B$ and $D$. Basket and stellate cells (Fig. $7 B, D$ ) as well 



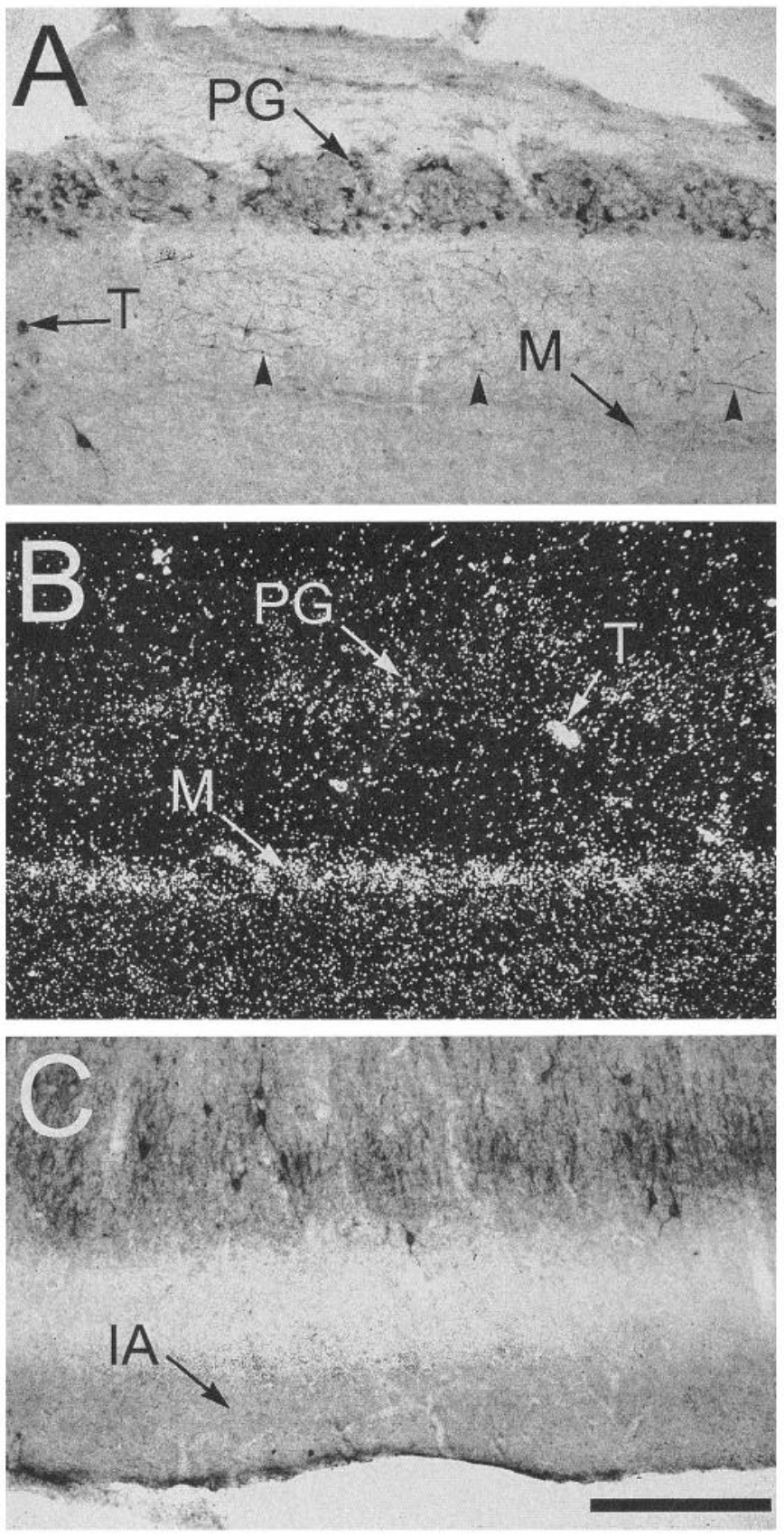

Figure 9. Localization of KV3.1b subunits in the olfactory bulb. Low power bright-field photomicrograph of the olfactory bulb $(A)$ and olfactory cortex $(C)$ following immunostaining with antibodies directed against KV3.1b specific peptides. (B) Low power dark-field photomicrograph following in situ hybridization of the olfactory bulb with probes specific for KV3.1. Note in $B$ that in situ hybridization probes label periglomerular cells $(P G)$, mitral cells $(M)$, and tufted cells $(T)$, while KV3.1b antibodies $(A)$ label only periglomerular and tufted cells. Note in $C$ the diffuse labeling of layer IA of the olfactory cortex. Scale bar: $A$ and $B, 178 \mu \mathrm{m} ; C, 300 \mu \mathrm{m}$. the dendrites of Purkinje cells (PCd, Fig. 8A) are seen as blank areas in the molecular cell layer. Throughout the parallel fibers we also see a strong punctate staining suggestive of labeling in terminal swellings (Fig. 7D).

Electron microscopy immunohistochemistry was used to confirm the presence of $\mathrm{KV} 3.1 \mathrm{~b}$ protein in granule cell axons (Fig. $8)$. The immunoreaction product is seen in patches in the membrane and underlying cytoplasm of granule cell's somata and dendrites (Fig. $8 B$ ) and in the synaptic boutons (b) of parallel fibers making synapses on Purkinje cell dendritic spines (Fig. $8 C$ ). Interestingly, in these boutons the label was usually not found near presynaptic vesicles, but rather it appears to be associated with axonal membrane away from the presynaptic membrane. There was no labeling of Purkinje cell dendritic spines in the molecular cell layer (s, Fig. $8 C$ ) or the mossy fibers in the granular cell layer (Fig. $8 D$ ).

Diffuse, usually faint, fiber-like labeling was also seen in many other areas with stained somas such as the globus pallidus (Fig. $4 B$ ), the caudate-putamen (Figs. $4 A, 5 E, 6 C, D$ ), and the inferior colliculus, the reticular formation, and the spinal cord (data not shown). These brain areas receive projections (see Paxinos, 1985) from neurons expressing KV3.1b mRNA, and usually also protein, such as the subthalamic nucleus (to the globus pallidus and the striatum), the cochlear and lateral lemniscus nuclei and the superior olive (to the inferior colliculus), the globus pallidus (to the subthalamic nucleus) and the thalamus (to the striatum). Moreover, staining of the neuropile is also observed in some areas lacking stained cell bodies such as the dorsal thalamus (Fig. $3 A$ ) which receives projections from many of the neurons expressing KV3.1b (i.e., the RT, SNr, SO, IC, $\mathrm{STh}, \mathrm{GP}$, reticular formation); the hypothalamus (Fig. $2 \mathrm{C}$ ) which receives projections from the septum among other areas; and in superficial layers of the superior colliculus (Fig. 2D). There is a major projection to the superior colliculus from the retina, but the expression of KV3.1b mRNAs or protein in this structure has not been studied. Nevertheless, superficial layers of the superior colliculus also receive axons from the ventral lateral geniculate which has immunostained somata (Table 1). Thus, it is likely that the immunostaining of the neuropile seen in many areas in the CNS is due to the presence of KV3.1b protein in projecting axons. Usually, the staining of the neuropile is weaker than that of somas. However, not all neurons expressing KV3.1b appear to have protein in their axons. For example, in spite of the fact that many neuronal populations (such as the pontine nuclei, the reticulotegmental nucleus of the pons and the reticular formation, Fig. $2 E, F$ ) projecting mossy fibers to the cerebellum are strongly labeled, we did not see evidence of mossy fiber staining (see Figs. $7 A, C ; 8 D$ ).

\section{$K V 3.16$ protein in the olfactory bulb}

Moderate to low levels of KV3.1 mRNAs were found by in situ hybridization in several neuronal populations in the olfactory bulb (Weiser et al., 1994; see also Fig. 9B). Most prominent was

Figure 8. Electron microscopic immunolocalization of KV3.1b in the cerebellum. A, Light microscope micrograph of a plastic embedded sagittal section through the cerebellar cortex from which sections for the electron microscope were cut. As shown previously, the molecular and granule cell layers are stained but not the Purkinje cells. In this orientation it is possible to see the unstained dendrites of Purkinje cells $(P C d)$ in the molecular cell layer as empty spaces surrounded by stained parallel fibers. $B-D$, Electron micrographs demonstrate patchy deposition of immunoreaction product in the plasma membrane and underlying cytoplasm of granule cell somata (arrowheads in $B$ and $D$ ) and dendrites (arrows in $B$ and $D)$, as well as in the synaptic boutons $(b$ in $C)$ of parallel fibers on unlabeled Purkinje cell dendritic spines $(s$ in $C)$. Mossy fiber terminals are not stained ( $m f$ in $D$ ). Scale bar: $A, 200 \mu \mathrm{m} ; B, 2.3 \mu \mathrm{m} ; C, 1.0 \mu \mathrm{m} ; D, 0.71 \mu \mathrm{m}$. 
Table 1. Neurons expressing KV3.1 mRNAs and KV3.1b somatic protein

Somat-

tic pro-

Region

Somatic mRNA

tein

Olfactory bulb

Periglomerular

Tufted cells

Mitral cells

Neocortex

Hippocampus

Interneurons

Pyramidal cells

Granule cells

Basal nuclei

Caudate putamen

Globus pallidus

Sth

Septum

Diagonal band

Medial septum

+++ (in a subset of neurons)

+++ (in a subset of cells)

$+(\mathrm{CA} 1),+(\mathrm{CA} 3)$

$+$

1 in scattered cells

$+$

$++$

$+$

$+$

$+$

Epithalamus

Pretectum

Lateral habenula

Dorsal thalamus

Ventral thalamus

Reticular thalamic nu.

Zona incerta

Ventral lateral geniculate

$+$

$+$

$+$

?

rain stem

Superior colliculus IGL

Inferior colliculus

SNR

Oculomotor nu.

Red nu.

Lateral lemniscus nuclei

$\mathrm{RtTg}$

Pontine nuclei

PNR

Cochlear nu. ventral

Spinal trigeminal nu.

Principal sensory trigeminal nu.

Motor trigeminal nu.

Superior olive

$\mathrm{Nu}$. trapezoid body

Vestibular nu. lateral

Vestibular nu. medial

Reticular formation

Hypoglossal nu.

$+$

$+($ in VPL, VPM $),+($ in AD, LD, LP, DLG)

?

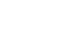

$++$

$++$

$+$

++ (in scattered neurons)

$+11$

$+1$

$+$

$++$

$+$

$++$

$+1$

$++$

$+$

$+$

$+$

$+$

+
+

$+$

$+$

$+$

$+$

$+$

Cerebellum

Granule cells

Deep cerebellar nu.

$+++$

$++$

$+$

Spinal cord

Dorsal horn

$++$

$\pm$

Ventral horn

mRNA column symbols: \pm , very weak hybridization signals; + , weak to moderate;,++ moderate to strong; +++ very strong. Protein column symbols: + , strong somatic staining; ?, inconclusive due to the lack of sufficient contrast between somatic and neuropile staining (see text); - , no somatic staining. Abbreviations: AD, anterodorsal thalamic nu.; DLG, dorsal lateral geniculate; IGL, intermediary gray layer; LD, laterodorsal thalamic nu.; LP, lateroposterior thalamic nu.; RtTg, reticulotegmental nucleus of the pons; SNR, substantia nigra pars reticulata; PNR, pontine reticular nu.; VPL, ventral posterolateral thalamic nu.; VPM, ventral posteriomedial thalamic nu. 
the labeling of the mitral cell layer. Tufted cells and the periglomerular area were also labeled. The KV3.1b antibodies label the soma of periglomerular cells and tufted neurons (Fig. 9A), but there is no staining of mitral cell somata. This represents one clear example where a cell type expressing KV3.1 mRNA has no detectable KV3.1b protein in the soma. However, there is weak diffuse labeling in layer $1 \mathrm{~A}$ of the piriform cortex (Fig. $9 C$ ), which may correspond to axonal projections of the mitral cells. Further studies are required to ascertain whether this labeling is indeed due to protein in axons from mitral cells. Faintly stained fibers were also seen in the external plexiform layer in the olfactory bulb (Fig. 9A), which could be secondary dendrites of mitral cells, axons or dendrites of tufted cells or afferent fibers.

\section{Discussion}

The data presented in this article, together with the results of mRNA expression (Perney et al., 1992; Weiser et al., 1994) illustrate the specific expression of KV3.1b subunits, one of the two known products of the KV3.1 gene, in the rat brain. The neuronal systems expressing highest levels of KV3.1b products include the granule cells of the cerebellum, neurons in the globus pallidus and the reticular thalamic nucleus as well as most of the central nuclei involved in auditory processing with the exception of the medial geniculate. As it has been pointed out before (Perney et al., 1992; Weiser et al., 1994), many, but not all, of the neurons expressing KV3.1b are GABAergic.

The availability of antibodies against the KV3.1b protein has also allowed us to identify the subset of neurons in the hippocampus that express this subunit as parvalbumin (PV) containing interneurons (Celio and Heizmann, 1981; reviewed in Celio, 1990) utilizing double staining methods. PV is believed to serve as a calcium buffer during bursts of action potentials and its presence is thought to correlate with fast firing properties (Celio and Heizmann, 1981; reviewed in Celio, 1990). The cells expressing KV3.1b in the cortex and the caudate-putamen were also found to correspond to PV containing neurons. Interestingly, principal neurons of the reticular thalamus, globus pallidus, inferior colliculus, substantia nigra pars reticulata, zona incerta, subthalamic nucleus, and lateral lemniscus nuclei, which cxpress KV3.1b protein, also contain PV, but notably granule cells of the cerebellum do not (Celio and Heizmann, 1981; Kozaka et al., 1987; reviewed in Celio, 1990).

At the subcellular level, most of the neuronal populations expressing KV3.1 mRNAs have somatic protein, although somatic staining was much stronger in some cases than others. The subunits also appear to be present in the axons of most, but perhaps not all, KV3.1b expressing neurons. In most cases the staining of the neuropil was weaker than the staining of cell bodies. In the cerebellum, the staining of the molecular cell layer is stronger than that of the granular cell layer. Our EM analysis suggests that this is due to the high density of parallel fibers in the molecular cell layer and not to increased levels of protein in the axon. The cellular and subcellular distribution of KV3.1b proteins shown in this article is different than that of the related KV3.2 subunits (Moreno et al., 1994).

These studies contribute to our knowledge of the arrays of distributions of $\mathrm{K}^{+}$channels in CNS neurons. and provide key information to select systems where one could search for native channels containing KV3.1b subunits. The identification of native KV3.1b channels is necessary to understand the functional role of these channel proteins.

\section{Toward the identification of native $K^{+}$channels containing} $K V 3.16$ proteins

In Xenopus oocytes KV3.1b proteins produce delayed rectifiertype or inactivating type- $\mathrm{A} \mathrm{K}^{+}$channels, depending on whether they are expressed alone, in combination with other Shaw-related subunits expressing delayed rectifiers (e.g., KV3.1a or KV3.2) or in combination with inactivating KV3.3 or KV3.4 Shaw-related subunits, as may well be the case in many neuronal populations expressing KV3.1b given the overlap in mRNA expression (Weiser et al., 1994). These inactivating subunits have a dominant effect in heteromultimers producing channels that inactivate at intermediary rates (Weiser et al., 1994). In all cases the channels start activating when the membrane is depolarized beyond $-20 \mathrm{mV}$ and are very sensitive to TEA and 4-AP.

However, native channels containing KV3.1b subunits could have properties different than those of homomultimeric or heteromultimeric KV3.1b channels in oocytes due to the effects of $\beta$ subunits or other factors that could influence channel function. For example, the $\beta_{1}$ subunit induces fast inactivation of delayed rectifier channels of the Shaker subfamily (Rettig et al., 1994); putative $\beta$-subunits of Shal proteins accelerate inactivation development and recovery and produce small shifts in voltage dependence (Covarrubias et al., 1993; Serodio et al., 1994). Even more dramatic are the effects of the $\beta$-subunit of the $\mathrm{Ca}^{2+}-\mathrm{ac}$ tivated maxi-K channel, including a $>50 \mathrm{mV}$ shift in voltage dependence (McManus et al., 1994).

The identification in this work of several neuronal somata expressing KV3.1b protein provides us with an opportunity to explore whether these cells have currents corresponding to those expressed by homomultimeric or heteromultimeric KV3.1b channels in oocytes.

Electrophysiological analysis of the $\mathrm{K}^{+}$currents in some of these neurons have been previously reported. However, these reports often do not have current separation methods appropriate to asccrtain whether there is oocyte-like KV3.1b currents. For example, in a patch-clamp study of dissociated globus pallidus neurons it was found that a significant portion of the outward current was blocked by $10 \mathrm{mM}$ TEA, but the components of this current were not characterized (Stefani et al., 1992). Similarly, a study of the voltage-gated channels of cerebellar granule cells was focused on the characterization of the subthreshold A current (Cull-Candy et al., 1989). Nevertheless, in Figure 6 of that study Cull-Candy et al. have plotted the values of the peak and maintained currents (during pulses of $\sim 100 \mathrm{msec}$ ) seen before and after application of $2 \mathrm{~mm} 4$-AP. From these plots it appears that the maintained component of the current that is blocked by $2 \mathrm{~mm}$ 4-AP starts activating at $\sim-10 \mathrm{mV}$. This current may correspond to $\mathrm{KV} 3.1 \mathrm{~b}$ channels, but further characterization is clearly required.

It is apparent that electrophysiological experiments specifically designed to search for currents with properties similar to those seen in vitro will be required to conclude whether cells expressing KV3.1b proteins have oocyte-like KV3.1b currents. Since many voltage-clamp studies from neurons utilize dissociated embryonic or early postnatal tissue, the availability of the antibodies will be helpful in the selection of conditions to obtain cells expressing the protein.

\section{Functional role of $K^{+}$channels containing $K V 3.1 b$ proteins}

KV3.1 proteins have been highly conserved throughout mammalian evolution suggesting that they play important and spe- 
cific roles, distinct from those of other related $\mathrm{K}^{\prime}$ channel subunits, and in particular from KV3.2 proteins which express currents with very similar properties in Xenopus oocytes (VegaSaenz de Miera et al., 1994).

If native $\mathrm{K}^{+}$channels containing $\mathrm{KV} 3 . \mathrm{lb}$ proteins are also activated when the membrane is depolarized beyond $-20 \mathrm{mV}$, as is the case for KV3.1 channels in oocytes, we may expect they will be activated mainly during action potentials or large receptor-mediated depolarizations. Such channels could be effective in repolarizing action potentials or postsynaptic depolarizations if they are present in large enough numbers, so that the current generated by the small fraction of channels that will open at the achieved voltages (and given the time available for opening) can overcome depolarizing currents. This may explain the abundant expression of KV3.1 (or KV3.2, Weiser et al., 1994) subunits in sensory neurons with high firing rates, as well as the correlation between KV3.1b and parvalbumin expression.

The predominant somatoaxonal localization of KV3.1b subunits is consistent with a role in action potential transmission by participating in the repolarization of action potentials. Heteromultimers of KV3.1 subunits with inactivating KV3.3 and KV3.4 proteins may also mediate changes in spike waveform during repetitive firing. The expression of $\mathrm{KV} 3.1 \mathrm{~b}$ subunits in somas, axons and their terminal fields suggests that these roles include the transmission of action potentials at the soma, their invasion of terminals and perhaps also the local regulation of neurotransmitter release. The low levels of expression in fine dendrites suggests that these channels play little role in the local integration of postsynaptic signals.

Why is a $\mathrm{K}^{+}$channel that might be used ineffectively conscrved throughout evolution if $\mathrm{K}^{+}$channels that activate at more negative voltages could also repolarize spikes? We can appreciate two differential effects between "high" $(>-20 \mathrm{mV})$ and "low" (>-40) voltage-activating channels that might be of physiological significance. First, high voltage activating $\mathrm{K}^{+}$ channels would have more selective effects. For example, channel activity at more negative voltages could decrease the probability of spike initiation more readily. Moreover, the role of the high voltage activating $\mathrm{K}^{+}$channels in shortening action potential duration will be restricted to the peak of the action potential. Second, if the $\mathrm{K}^{+}$current through the high voltage-activating channels turns off quickly, as it does in oocytes, the membrane resistance immediately following the spike will be higher. This may be helpful in the generation of multiple spikes during spike trains or spike bursts. In a cell containing both types of channels, their modulation by different second messenger systems may allow the cell to regulate action potential duration independently from action potential generation.

Although KV3.1 and KV3.2 transcripts express similar currents in heterologous expression systems, they are modulated by different second messenger systems (Moreno et al., 1994) and are expressed for the most part in different neuronal populations, including a different subset of interneurons in the cortex and hippocampus (Weiser et al., 1994). They also appear to be expressed in different subcellular compartments (Moreno et al., 1994). It is thus possible that the channels containing both types of proteins have similar roles on excitation but play specific roles in different cells depending on their response to modulatory second messenger pathways.

\section{Compartmentalization of $K^{+}$channels}

Although there are striking examples of ion channel segregation to specific membrane regions in different cell types (see reviews by Almers and Sterling, 1984; chapter 19 of Hille, 1992; Rodriguez-Boulan and Powell, 1992; Froehner, 1993; Kelly and Grote, 1993), and there is a clear appreciation of the functional significance of channel segregation in neuronal integration (Llinas, 1988; Shepherd, 1990; Kandel et al., 1991; Hille, 1992), little is known about the distribution of voltage-gated ion channels, particularly $\mathrm{K}^{+}$channels, in mammalian CNS neurons. The progress made on the molecular biology of $\mathrm{K}^{+}$channel proteins has opened the possibility of investigating the segregation of $\mathrm{K}^{+}$ channcls in CNS ncurons by following an immunocytochemical approach such as the one utilized here and in other recent works (Trimmer et al., 1991; Sheng et al., 1992; Hwang et al., 1993; Sheng et al., 1994; Wang et al., 1994).

The $\mathrm{K}^{+}$channels investigated thus far demonstrate the existence of various characteristic distributions. KV4.2 proteins, for example, have a somatodendritic localization, predominating in dendrites rather than somas, and are present throughout the dendritic tree, including fine dendritic processes (Sheng et al., 1992). These subunits, which are key components of low voltage activating A channels (Baldwin et al., 1991; Blair et al., 1991; Pak et al., 1991; Serodio et al., 1994), are thus likely to influence postsynaptic integration of input signals. On the other hand, KV1.4 subunits are expressed mainly in axonal terminals (Sheng et al., 1992).

The Shaker-related $\mathrm{K}^{+}$channels KV1.1 and KV1.2 have a variable distribution, depending on the neuronal population. They are present in presynaptic terminals, in the juxtaparanodal region of myelinated axons, in unmyelinated axons, in somas and dendrites (Sheng et al., 1994; Wang et al., 1994). However, the distribution of levels of expression between these compartments vary among distinct neuronal populations.

$\mathrm{KV} 3.1 \mathrm{~b}$ is expressed predominantly in somatic and axonal membranes. Immunostaining was also seen in proximal dendrites of most somas containing protein, but not usually in fine dendrites, in contrast to the dendritic staining with KV4.2 and sometimes with KV1.2 antibodies. For example, both KV4.2 and $\mathrm{KV} 3.1 \mathrm{~b}$ are present in the granular cell layer of the cerebellum. However, while the antibodies against KV4.2 immunostain predominantly the glomeruli, where granule cell dendrites contact mossy fibers, with KV3.1b antibodies, the glomeruli are only faintly stained as compared to granule cell somata (compare Fig. $7 B, C$ with $6 G-J$ in Sheng et al., 1992).

The pattern of distribution of KV3.1b is more similar to that displayed by KV1.1 and KV1.2 in some neurons. KV1.1 and/or KV1.2 may actually coexist with KV3.1b in these neurons (compare the distribution described here with that of KV1.1 and KV1.2 in Wang et al., 1994; Sheng et al., 1994), such as the cell bodies and proximal dendrites of neurons in deep cerebellar nuclei, pontine reticular nucleus, the septum, olfactory bulb tufted cells, superior olive and globus pallidus. They may also coexist in several axonal membranes and nerve terminals. KV1.4 proteins (Sheng et al., 1992) also overlap with KV3.1b subunits in some CNS terminals.

There are, however, two differences between the pattern of expression of KV3.1b and the distribution of KV1.1 and KV1.2 even in the same cells which can be of considerable functional significance: (1) in most neuronal populations the immunostaining with KV3.1b antibodies is strongest in somas, while KV1.2 is reportedly generally weaker in somas than in other parts of the cell; and (2) although the staining of axonal terminal fields with KV3.1b antibodies appears to be extensive, the main nerve trunks carrying the projections of many of the neurons express- 
ing KV3.1b protein are not significantly stained. For exante, the lateral lemniscus (Fig. $2 E$ ) displays little staining although neurons in the cochlear nuclei and nuclei of the lateral lemniscus clearly express KV3:1b protein and axonal-like staining in the inferior colliculus is extensive. This is in contrast to the staining of white matter in some brain areas with KV1.1 and KV1.2 antibodies, and probably reflects lower levels of KV3.1b protein in myelinated vs. unmyelinated axons. However, further experiments are required to investigate these differences between KV3.1b, KV1.1, and KV1.2 localization, since it remains possible that some of them are the result of differences in technique.

Specific molecular mechanisms must exist to achieve these distinct distributions. These include signals present in the channel subunits themselves or in accessory subunits, as well as anchoring to specific intracellular proteins, differential extracellular interactions or posttranslational processing (Rodriguez-Boulan and Powell, 1992; Froehner, 1993; Kelly and Grote, 1993; Pelham and Munro, 1993). Immunoblots of membrane proteins from different brain areas showed small but reproducible differences in the size of the proteins recognized by the KV3.1b antibodies (Fig. 1C). As stated earlier these may reflect differences in posttranslational processing which may contribute to differences in subcellular localization in distinct neuronal populations.

Given that Sh subunits of the same subfamily can form heteromultimeric channels, the subcellular localization of an heteromultimer may be dictated by one of the subunits as seen for $\mathrm{GABA}_{\mathrm{A}}$ receptor subunits (Perez-Velazquez and Angelides, 1993). This may explain the variable distribution of Shaker-related KV1.1 and KV1.2 in different neurons (Sheng et al., 1994; Wang et al., 1994). These proteins may be forming heteromultimers among themselves and with five more known Shakerrelated subunits many of which have a wide distribution in the CNS. Hctcromultimer formation of KV3.1b proteins with other Shaw-related subunits having different distributions and targeting sequences may similarly explain the differences in relative levels of KV3.1b protein in somas versus axons in different neurons. Analysis of the subcellular localization of other Shaw subunits, and in particular KV3.3 proteins, may help find the source of targeting signals.

The limited ultrastructural analysis demonstrates details of the localization of KV3.1b proteins that deserve further study. KV3.1b proteins appear to be present in patches in the membrane of cerebellar granule cells (Fig. 8). Loose-patch clamp studies have also suggested a patchy distribution for a number of channels in different cell types (Almers and Sterling, 1984; Roberts et al., 1990; see also chapter 19 in Hille, 1992). This may have interesting functional consequences and has implications regarding molecular mechanisms of channel localization. We have also found that although KV3.1b protein is present in terminal boutons, it seems to be localized away from the membrane immediately opposite presynaptic vesicles.

\section{References}

Almers W, Stirling CE (1984) The distribution of transport proteins over animal cell membranes. J Membr Biol 77:169-186.

Baldwin TJ, Tsaur ML, Lopez GA, Jan YN, Jan LY (1991) Characterization of a mammalian cDNA for an inactivating voltage-sensitive $\mathrm{K}^{+}$channel. Neuron 7:471-483.

Black JA, Friedman B, Waxman SG, Elmer LW, Angelides KJ (1989) Immuno-ultrastructural localization of sodium channels at nodes of Ranvier and perinodal astrocytes in rat optic nerve. Proc R Soc Lond [Biol] 238:39-51.

Blair TA, Roberds SL, Tamkun MM, Hartshorne RP (1991) Functional characterization of RK5, a voltagc-gated $\mathrm{K}^{+}$channcl cloned from the rat cardiovascular system. FEBS Lett 295:211-213.

Carpenter MB, Carleton SC, Keller JT, Conte P (1981a) Connections of the subthalamic nucleus in the monkey. Brain Res 224:1-29.

Carpenter MB, Batton RR III, Carleton SC, and Keller JT (1981b) Interconnections and organization of pallidal and subthalamic nucleus neurons in the monkey. J Comp Neurol 197:579-603.

Celio MR (1990) Calbindin D-28k and parvalbumin in the rat nervous system. Neuroscience 35:375-475

Celio MR, Heizmann CW (1981) Calcium-binding protein parvalbumin as a neuronal marker. Nature 293:300-302.

Chabala LD, Bakry N, Covarrubias M (1993) Low molecular weight poly $(\mathrm{A})^{+}$mRNA species encode factors that modulate gating of a non-Shaker A-type $\mathrm{K}^{+}$channel. J Gen Physiol 102:713-728.

Chandy KG, Douglas J, Gutman GA, Jan L, Joho R, Kaczmarek L, McKinnon D, North RA, Numa S, Philipson L, Rivera AB, Rudy B, Salkoff L, Swanson R, Steiner D, Tanouye M, Tempel BL (1991) Simplified gene nomenclature. Nature 352:26.

Christie MJ, North RA, Osborne PB, Douglass J, Adelman JP (1990) Heteropolymeric potassium channels expressed in Xenopus oocytes from cloned subunits. Neuron 4:405-411.

Covarrubias M, Wei A, Salkoff L (1991) Shaker, Shal, Shab, and Shaw express independent $\mathrm{K}^{+}$current systems. Neuron 7:763-773.

Cull-Candy SG, Marshall CG, Ogden D (1989) Voltage-activated membrane currents in rat cerebellar granule neurons. J Physiol (Lond) 414:179-199.

Ellisman MH, Levinson SR (1982) Immunocytochemical localization of sodium channel distributions in the excitable membranes of Electrophorus electricus. Proc Natl Acad Sci USA 79:6707-6711.

Erickson AH, Blobel G (1983) Cell-free translation of messenger RNA in a wheat germ system. Methods Enzymol 96:38-50.

Froehner SC (1993) Regulation of ion channel distribution at synapses. Annu Rev Neurosci 16:347-368.

Hammond C, Yelnik J (1983) Intracellular labeling of rat subthalanic neurones with horseradish peroxidase: computer analysis of dendrites and characterization of axon arborization. Neuroscience 8:781-790.

Harlow E, Lane D (1988) Antibodies: a laboratory manual. Cold Spring Harbor, NY: Cold Spring Harbor Laboratory.

Hartshorne RP, Catterall WA (1984) The sodium channel from rat brain. Purification and subunit composition. J Biol Chem 259:16671675

Hille B (1992) Ionic channels of excitable membranes, 2d ed. Sunderland, MA: Sinauer.

Hillman D, Chen S, Aung T, Cherksey B, Sugimori M, Llinas R (1991) Localization of P-type calcium channels in the central nervous system. Proc Natl Acad Sci USA 88:7076-7080.

Hwang PM, Fotuhi M, Bredt DS, Cunningham AM, Snyder SH (1993) Contrasting immunohistochemical localizations in rat brain of two novel $\mathrm{K}^{+}$channels of the Shab subfamily. J Neurosci 13:1569-1576.

Isacoff EY, Jan YN, Jan LY (1990) Evidence for the formation of heteromultimeric potassium. channels in Xenopus oocytes. Nature 345:530-534.

Jan L-Y, Jan Y-N (1990) How might the diversity of potassium channels be generated? Trends Neurosci 13:415-419.

Kandel ER, Schwartz JH, Jessell TM (1991) Principles of neural science, $3 d$ ed. New York: Elsevier.

Katsumaru H, Kosaka T, Heizmann CW, Hama K (1988) Immunocytochemical study of GABAergic neurons containing the calciumbinding protein parvalbumin in the rat hippocampus. Exp Brain Res 72:347-362.

Kelly RB, Grote E (1993) Protein targeting in the neuron. Annu Rev Neurosci 16:95-127.

Kosaka T, Katsumaru H, Hama K, Wu J-Y, Heizmann CW (1987) GA$\mathrm{B} \wedge$ ergic neurons containing the $\mathrm{Ca}^{++}$-binding protein parvalbumin in the rat hippocampus and dentate gyrus. Brain Res 419:119-130.

Llinas R (1988) The intrinsic electrophysiological properties of mammalian neurons: insights into central nervous system function. Science 242:1654-1664.

Luneau CJ, Williams JB, Marshall J, Levitan ES, Oliva C, Smith JS, Antanavage J, Folander K, Stein RB, Swanson R, Kaczmarek L, Buhrow SA (1991) Alternative splicing contributes to $K$ channel diversity in the mammalian central nervous system. Proc Natl Acad Sci USA 88:3932-3936.

McCormack K, Lin JW, Iverson L, Rudy B (1990) Shaker $K^{+}$channel 
subunits form heteromultimeric channels with novel functional properties. Biochem Biophys Res Commun 171:1361-1371.

McCormack T, Vega-Saenz de Miera E, Rudy B (1990) Molecular cloning of a member of a third class of Shaker-family $\mathrm{K}^{+}$channel genes in mammals. Proc Natl Acad Sci 87:5227-5231.

McManus OB, Pallanck L, Helms LM, Swanson R, Leonard RJ (1994) The beta subunit of maxi- $\mathrm{K}$ channels modifies gating and pharmacology of expressed mslo channels. Soc Neurosci Abstr 20:722.

Moreno H, Kentros C, Bueno E, Weiser M, Hernandez A, Vega-Saenz de Miera A, Ponce A, Thornhill W, Rudy B (1995) Thalamocortical projections have a $\mathrm{K}^{+}$channel that is phosphorylated and modulated by cAMP-dependent protein kinase. $\mathbf{J}$ Neurosci 15 : in press.

Pak MD, Baker K, Covarrubias M, Butler A, Ratcliffe A, Salkoff L (1991) mShal, a subfamily of A-type $\mathrm{K}^{+}$channels cloned from mammalian brain. Proc Natl Acad Sci USA 88:4386-4390.

Paxinos G (1985) The ral nervous system, 1. New York: Acadenic.

Paxinos G, Watson C (1986) The rat brain in stereotaxic coordinates, 2d ed. Boca Raton, FL: Academic.

Pelham HR, Munro S (1993) Sorting of membrane proteins in the secretory pathway. Cell 75:603-605.

Perez-Velazquez JL, Angelides K (1993) Assembly of GABA-A receptor subunits determines sorting and localization in polarized cells. Nature 361:457-460.

Perney TM, Kaczmarek LK (1991) The molecular biology of K channels. Curr Opin Cell Biol 3:663-670.

Perney TM, Marshall J, Martin KA, Hockfield S, Kaczmarek LK (1992) Expression of the mRNAs for the Kv3.1 potassium channel gene in the adult and developing rat brain. J Neurophysiol 68:756-766.

Pongs O (1992) Molecular biology of voltage-dependent potassium channels. Physiol Rev [Suppl] 72:S79-S88.

Rettig J, Heinemann SH, Wunder F, Lorra C, Parcej DN, Dolly JO, Pongs O (1994) Inactivation properties of voltage-gated K+ channels altered by the presence of $\beta$-subunit. Nature 369:289-294.

Roberts WM, Jacobs RA, Hudspeth AJ (1990) Colocalization of ion channels involved in frequency selectivity and synaptic transmission in presynaptic active zones of hair cells. J Neurosci 10:3664-3684.

Rodriguez-Boulan E, Powell SK (1992) Polarity of epithelial and neuronal cells. Annu Rev Cell Biol 8:395-427.

Rudy B (1988) Diversity and ubiquity of K channels. Neuroscience 25:729-750.

Rudy B, Hoger JH, Lester HA, Davidson N (1988) At least two mRNA species contribute to the properties of rat brain A-type potassium channels expressed in Xenopus oocytes. Neuron 1:649-658.

Rudy B, Kentros C, Vega-Saenz de Miera E (1991a) Families of K channel genes in mammals: toward an understanding of the molecular basis of K channel diversity. Mol Cell Neurosci 2:89-102.

Rudy B, Sen K, Vega-Saenz de Miera E, Lau D, Ried T, Ward DC (1991b) Cloning of a human cDNA expressing a high voltage-activating, TEA-sensitive, type-A K channel gene which maps to chromosome 1 band p21. J Neurosci Res 29:401-412.

Rudy B, Kentros C, Weiser M, Fruhling D, Serodio P, Vega-Saenz de Miera E, Ellisman MH, Pollock JA, Baker H (1992) Region-specific expression of a $\mathrm{K}^{+}$channel gene in brain. Proc Natl Acad Sci USA 89:4603-4607.

Ruppersberg JP, Schrotter KH, Sakmann B, Stocker M, Sewing S, Pongs O (1990) Heteromultimeric channels formed by rat brain potassiumchamel proteins. Nature 345.535-537.

Salkoff L, Baker K, Butler A, Covarrubias M, Pak MD, Wei A (1992) An essential "set" of $\mathrm{K}^{+}$channels conserved in flies, mice and humans. Trends Neurosci 15:161-166.

Scott VES (1994) Proc Natl Acad Sci USA 91:1637-1641

Serodio P, Kentros C, Rudy B (1994) Identification of molecular components of A-type channels activating at subthreshold potentials. J Neurophysiol 72:1516-1529.

Sheng M, Tsaur M-L, Jan YN, Jan LY (1992) Subcellular segregation of two A-type $\mathrm{K}^{+}$channel proteins in rat central neurons. Neuron 9:271-284.

Sheng M, Tsaur M-L, Jan YN, Jan LY (1994) Contrasting subcellular localization of the KV1.2 $\mathrm{K}^{+}$channel subunit in different neurons of rat brain. J Neurosci 14:2408-2417.

Shepherd GM (1990) The synaptic organization of the brain, 3d ed. New York: Oxford UP.

Sloviter RS (1989) Calcium-binding protein (calbindin- $D_{28 k}$ ) and parvalbumin immunocytochemistry: localization in the rat hippocampus with specific reference to the selective vulnerability of hippocampal neurons to seizure activity. J Comp Neurol 280:183-196.

Stefani A, Calabresi P, Mercuri NB, Bernardi G (1992) A-Current in rat globus pallidus: a whole-cell voltage clamp study on acutely dissociated neurons. Neurosci Lett 144:4-8.

Trimmer JS (1991) Immunological identification and characterization of a delayed rectifier $\mathrm{K}^{+}$channel polypeptide in rat brain. Proc Natl Acad Sci USA 88:10764-10768.

Vega-Saenz de Miera E, Moreno H, Fruhling D, Kentros C, Rudy B (1992) Cloning of ShIII (Shaw-like) cDNAs encoding a novel highvoltage-activating, TEA-sensitive, type-A K $\mathrm{K}^{+}$channel. Proc R Soc Lond [Biol] 248:9-18.

Vega-Saenz de Miera E, Weiser ME, Kentros C, Lau D, Moreno H, Serodio P, Rudy B (1994) Shaw-related $\mathrm{K}^{+}$channels in mammals. In: Handbook of membrane channels, pp 41-78. New York: Academic.

Wang H, Kunkel DD, Martin TM, Schwartzkroin PA, Tempel BL (1993) Heteromultimeric $\mathrm{K}$ channels in terminal and juxtaparanodal regions of neurons. Nature 365:75-79.

Wang H, Kunkel DD, Schwartzkroin PA, Tempel BL (1994) Localization of $\mathrm{Kvl} .1$ and $\mathrm{Kv} 1.2$, two $\mathrm{K}$ channel proteins, to synaptic terminals, somata and dendrites in the mouse brain. J Neurosci 14:45884599.

Warmke JW, Ganetsky B (1994) Proc Natl Acad Sci USA 91:34383442.

Weiser M, Vega-Saenz de Miera E, Kentros C, Moreno H, Franzen L, Hillman D, Baker H, Rudy B (1994) Differential expression of Shaw-related $\mathrm{K}^{+}$channels in the rat central nervous system. J Neurosci 14:949-972.

Yokoyama S, Imoto K, Kawamura T, Higashida $\mathrm{H}$, Iwabe $\mathrm{N}$, Miyata $\mathrm{T}$, Numa S (1989) Potassium channels from NG108-15 neuroblastomaglioma hybrid cells. FEBS Lett 259:37-42. 